\title{
ESTUDO GENÉTICO PROSPECTIVO DE RECÉM-NASCIDOS E NATIMORTOS COM DEFEITOS CONGÊNITOS
}

Dissertação apresentada a Instituto de
Biociências, Letras e Ciências Exatas (IBILCE/UNESP) - São José do Rio Preto para obtenção do título de Mestre em Genética.

Orientadora: Profa. Dra. Agnes Cristina Fett Conte. 
CAMILA IVE FERREIRA OLIVEIRA

\title{
ESTUDO GENÉTICO PROSPECTIVO DE RECÉM-NASCIDOS E NATIMORTOS COM DEFEITOS CONGÊNITOS
}

\author{
Dissertação apresentada ao Instituto de \\ Biociências, Letras e Ciências Exatas \\ (IBILCE/UNESP) - São José do Rio Preto para \\ obtenção do título de Mestre em Genética.
}

COMISSÃO JULGADORA

Presidente e Orientadora: Profa. Dra. Agnes Cristina Fett Conte

2ํㅡㄹ Examinador: Profa. Dra. Roseli Maria Zechi Ceide

$3^{\circ}$ Examinador: Prof. Dr. Luiz Carlos de Mattos

São José do Rio Preto, 26/02/2010. 
Nós não devemos deixá-los de lado e pensarmos neles como algo inútil ou tratálos como "curiosidades" ou "casualidades". Nenhum deles é desprovido de significado; e não há nenhum que não possa proporcionar um excelente conhecimento se apenas pudermos responder à questão: por que é raro? Ou, sendo raro, por que, neste caso, aconteceu?

JAMES PAGET, Lancet, 2:1017, 1882 


\section{Agradecimentos}

À minha orientadora, Profa. Dra. Agnes Cristina Fett Conte, pela confiança depositada e dedicação na orientação deste trabalho.

A todos os membros da equipe do Laboratório de Genética pelo companheirismo e colaboração: Adriana Gonçalves, Ana Luiza Martins, Andrea Salles, Brasilina Mafei, Carlos Fabián Mendiburu, Cristina Goloni, Marcos Micheletto, Paula Abdala, Paula Freitas e Valéria Ferrarese.

Aos docentes e médicos residentes dos Serviços de Pediatria e de Ginecologia e Obstetrícia do Hospital de Base, que contribuíram com a realização deste trabalho solicitando a avaliação dos pacientes.

A Profa. Dra. Denise Cristina Móz Vaz e ao Centro Interdepartamental de Medicina Fetal, do Hospital de Base, pelo apoio e oportunidade de frequentar as reuniões multidisciplinares para discussão dos casos.

Ao Prof. Dr. Antonio Richieri da Costa pela atenção e relevante colaboração na elucidação dos diagnósticos.

Aos pais e mães responsáveis pelos bebês, que gentilmente confiaram na equipe e colaboraram para o desenvolvimento deste estudo.

Aos membros da banca examinadora, pela disponibilidade, atenção e sugestões.

A Coordenação de Aperfeiçoamento de Pessoal de Nível Superior (CAPES), pelo auxílio financeiro concedido para o desenvolvimento deste projeto.

A Fundação Faculdade Regional de Medicina de São José do Rio Preto (FUNFARME) pela disposição das condições materiais para a execução deste trabalho.

Ao Instituto de Biociências, Letras e Ciências Exatas, IBILCE/UNESP e ao Programa de Pós Graduação em Genética pelos ensinamentos científicos adquiridos.

Aos meus pais, Maria Neusa e Florisvaldo Oliveira, pelo incentivo ao ensino e principalmente por todo carinho e atenção, ao meu irmão Vinicius Igor Oliveira e a todos meus familiares, por todo apoio.

Aos meus amigos, pelo "suporte", obrigada! 


\section{Resumo}

Os defeitos congênitos resultam de causas genéticas e não genéticas, afetam cerca de 3 a 5\% dos recém-nascidos e são reconhecidos como uma das maiores causas de morbidade e mortalidade no primeiro ano de vida, além de serem a causa de muitas mortes embrionárias e fetais. Possuem etiologia e fatores de risco variados, muitos ainda desconhecidos. Dados epidemiológicos brasileiros são escassos. O estudo dos fatores epidemiológicos pode ampliar o conhecimento sobre tais defeitos e propiciar estratégias de prevenção, além do Aconselhamento Genético adequado para as famílias envolvidas. O presente trabalho realizou um estudo genético clínico prospectivo de todos os recém-nascidos e natimortos com defeitos congênitos atendidos no período de um ano no Hospital de Base de São José do Rio Preto/SP (HB), com o objetivo de estimar a prevalência, caracterizar em tipos de doenças, diagnósticos ou categorias diagnósticas, verificar as possíveis causas e consequências dos defeitos. Para cada criança foi realizada a análise cariotípica (nos casos indicados), a avaliação física, o registro fotográfico, análise de dados de prontuário médico e coleta de informações complementares com a família. Foram estudados 110 indivíduos, 103 recém-nascidos e sete natimortos. A prevalência foi de $2,8 \%$. Em $82 \%$ dos casos o diagnóstico específico pode ser sugerido. Os defeitos congênitos de etiologia genética foram mais frequentes que os de etiologia não genética. Os de herança multifatorial foram os mais freqüentes $(29 \%)$, seguidos dos de etiologia heterogênea (22\%), monogênica (19\%), desconhecida (13,5\%), cromossômica (12\%) e ambiental (4,5\%). A idade materna, a consangüinidade parental e a predisposição familial (presença de defeitos congênitos na família) foram alguns fatores de risco identificados. A maioria dos afetados eram prematuros e a hospitalização prolongada e o óbito foram as consequências mais observadas. Portanto, os defeitos congênitos são frequentes na população, derivam de diversas causas, sendo o componente genético um dos mais importantes, e suas consequências podem ser graves. O conhecimento sobre tais defeitos possibilita a elaboração de estratégias preventivas, terapêuticas e o Aconselhamento Genético adequado para as famílias.

Palavras-chave: Defeitos Congênitos, Malformações Congênitas, Estudo Genético, Recémnascido, Natimorto. 


\section{Abstract}

Birth defects, resulting from genetic and non-genetic causes, affect about 3 to $5 \%$ of newborns and are recognized as a major cause of morbidity and mortality within the first year of life, as well as being the cause of many embryonic and fetal deaths. Not infrequently the varied etiology and risk factors remain unknown. Brazilian epidemiological data are scarce. The study of epidemiological factors may increase knowledge about these defects and make prevention strategies and genetic counseling possible for affected families. This work constitutes a prospective clinical genetic study of all newborn and stillborn infants with birth defects seen over one year in Hospital de Base in São José do Rio Preto, Sao Paulo, in order to estimate the prevalence, characterize the disease types, diagnoses or diagnostic categories and evaluate possible causes and consequences of the defects. Karyotypic analysis, a physical assessment, photographic records, an analysis of the patients' medical records and the collection of additional information with the family was performed for each infant. The study assessed 103 newborn and 7 stillborn subjects. The prevalence of birth defects was of $2.8 \%$. A specific diagnosis was suggested in $82 \%$ of cases. Genetically-related birth defects were more prevalent than those with non-genetic etiology. Infants with multifactorial inheritance patterns were the most common (29\%), followed by heterogeneous etiology (22\%), monogenic inheritance patterns (19\%), unknown (13,5\%), chromosomal etiologies $(12 \%)$ and environmental factors (4.5\%). Maternal age, parental consanguinity and family susceptibility (the presence of defects in the family) were some of the identified risk factors. Most affected infants were premature and the most commonly observed consequences were prolonged hospital stays and death. Hence, birth defects are frequent in the population; several causes are involved with the genetic component being one of the most common, and the consequences can be severe. Knowledge of such defects makes the development of therapeutic and preventive strategies and adequate Genetic Counseling possible for families.

Keywords: Birth Defects, Congenital Malformation, Genetic study, Newborn, Stillborn. 


\section{Lista de Figuras}

Figura 1. Frequências dos DC decorrentes de causa monogênica, cromossômica, multifatorial e ambientalsociados, com destaque para politelia bilateral.

Figura 2. Paciente com defeitos associados, com destaque para politelia bilateral.................33

Figura 3. Paciente com Displasia Torácica de Jeune - corpo inteiro(a) e face (b)................. 33

Figura 4. Paciente com fissura labial e palatina. …................................................................. 35

Figura 5. Paciente com Hipocondroplasia, com destaque para redução do tamanho dos membros. 36

Figura 6. Paciente com politelia bilateral indicada pelas setas. …......................................... 36

Figura 7a-f. Pacientes diagnosticados com síndrome de Down........................................... 38

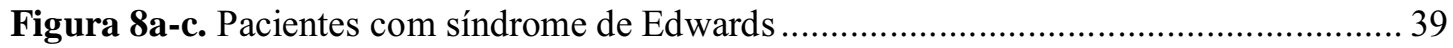

Figura 9. Paciente diagnosticado com síndrome de Patau. Aspecto facial (a), polidactilia (b) e onfalocele (c).

Figura 10. Pacientes com diagnóstico concluído. RN com anomalia anorretal (a); NT com complexo membro parede (b); NT com DFTN-mielomeningocele (c); RN com hidroanencefalia (d); RN com displasia tanatofórica tipo II (e); RN com fenda labial (f); $\mathrm{RN}$ com gastrosquise (g); $\mathrm{RN}$ com pé torto congênito (h) 43

Figura 11. Pacientes com diagnóstico concluído. RN com sequência da displasia caudal (a); RN com sequência da ruptura anmiótica (b); RN com síndrome de Moebius (c); RN com síndrome da artogripose distal (d); RN com síndrome de Barbey-Say (e); RN com síndrome de Larsen (f); RN com síndrome de Prune-Belly (g); RN com síndrome de Townes Brocks (h). $\quad 44$

Figura 12. Pacientes com diagnóstico presumido. RN com suspeita de Atelosteogênese tipo III* (a); RN com síndrome de Pfeiffer (b); RN com síndrome Velocardiofacial (c). 45

Figura 13a-h. Pacientes com defeitos múltiplos. 46 


\section{Lista de Gráficos}

Gráfico 1. Distribuição da idade materna na população estudada......................................... 32

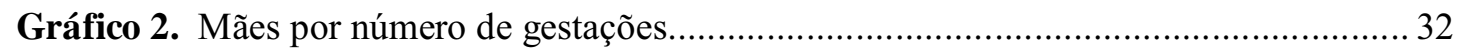

Gráfico 3. Frequência de todos os casos por diagnóstico....................................................... 42 


\section{Lista de Tabelas}

Tabela 1. Frequências de casos de acordo com as variáveis estudadas.

Tabela 2. Distribuição segundo êxito das culturas celulares para análise citogenética dos cariótipos realizados

Tabela 3. DC com diagnósticos concluídos, presumidos $\left(^{*}\right)$ e desconhecidos (defeitos múltiplos - **) com etiologia de acordo com os dados obtidos da literatura. 41

Tabela 4. Frequência dos DC por etiologia 


\section{Lista de Abreviaturas e Siglas}

$\begin{array}{ll}\text { CIMEFE } & \text { Centro Interdepartamental de Medicina Fetal } \\ \text { DC } & \text { Defeitos congênitos } \\ \mathrm{cm} & \text { Centímetros } \\ \text { DMG } & \text { Diabetes mellitus gestacional } \\ \text { DFTN } & \text { Defeito de Fechamento de Tubo Neural } \\ \text { ECLAMC } & \text { Estudo Colaborativo Latino Americano de Malformações Congênitas } \\ \text { FAMERP } & \text { Faculdade de Medicina de São José do Rio Preto } \\ \text { FUNFARME } & \text { Fundação Faculdade Regional Medicina } \\ \text { g } & \text { Gramas } \\ \text { HB } & \text { Hospital de Base de São José do Rio Preto } \\ \text { NT } & \text { Natimorto(s) } \\ \text { RN } & \text { Recém-nascido(s) } \\ \text { UTI } & \text { Unidade de Terapia Intensiva }\end{array}$




\section{Sumário}

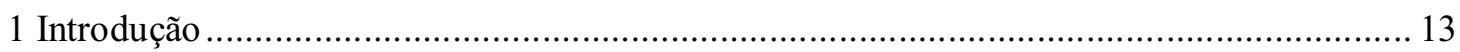

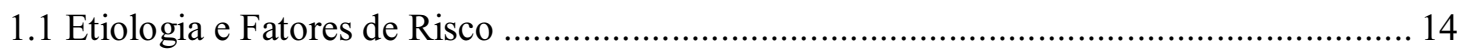

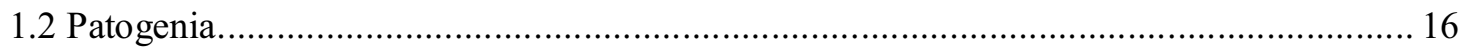

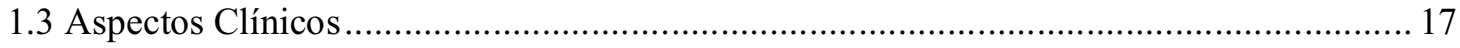

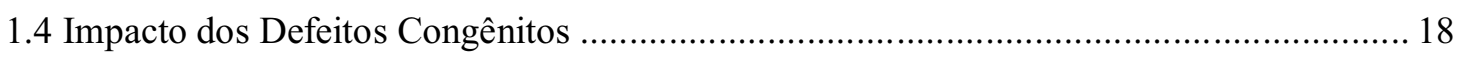

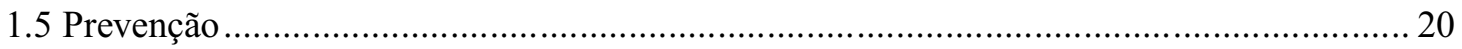

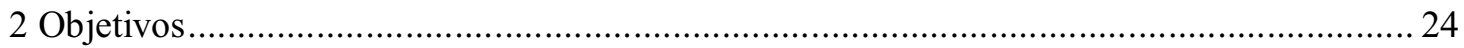

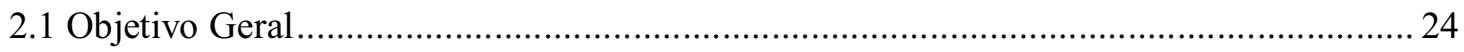

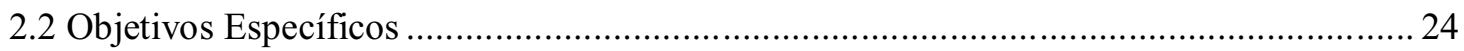

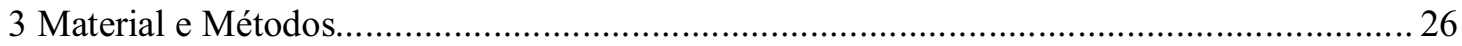

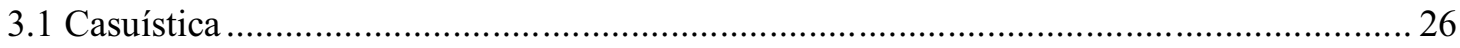

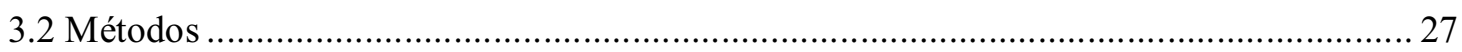

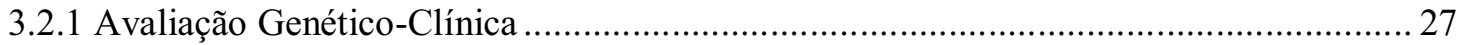

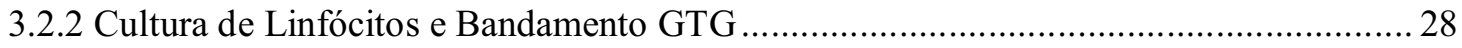

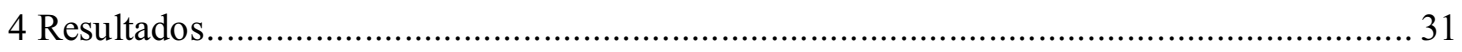

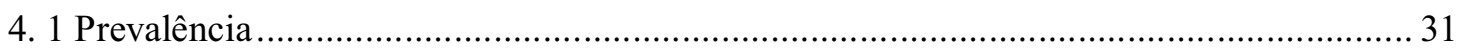

4. 2 Variáveis Maternas, Paternas e Características Obstétricas de Importância Perinatal....... 31

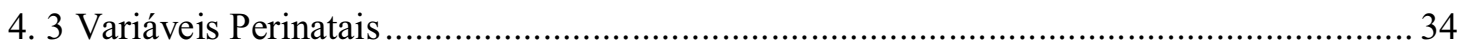

4.4 Recorrência Familial do Defeito Congênito …............................................................... 35

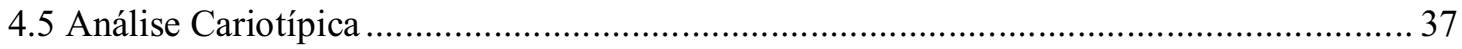

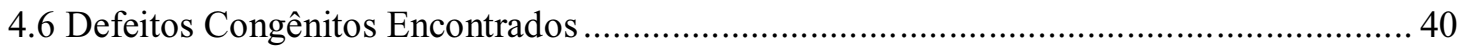

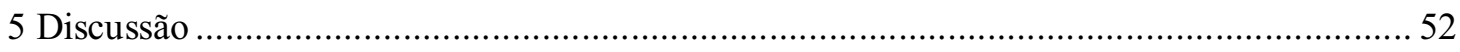

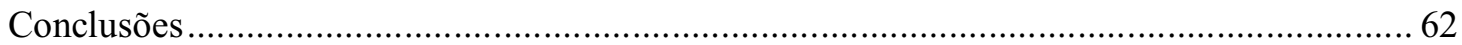




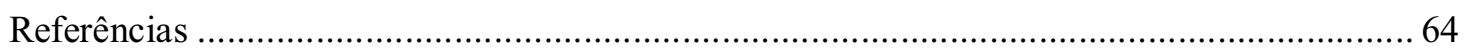

ANEXO A - Termo de Consentimento Livre e Esclarecido.................................................... 77

ANEXO B - Protocolo de Pesquisa de Recém-Nascidos e Natimortos com DC 80 


\section{INTRODUÇÃO}

Defeito congênito (DC), ou anomalia congênita, inclui toda alteração funcional ou estrutural do desenvolvimento embrionário ou fetal, originada antes do nascimento e presente no mesmo, decorrente de causa genética, ambiental ou desconhecida, que resulta em comprometimento físico e/ou mental do indivíduo. Podem ser únicos ou múltiplos, de significado clínico maior ou menor (HARPER, 2000; CALONE et al., 2009).

\subsection{Etiologia e Fatores de Risco}

Os DC representam um grupo complexo e heterogêneo de distúrbios do desenvolvimento embrionário e/ou fetal, que em cerca de $50 \%$ dos casos não têm causa conhecida. Os de etiologia genética são os mais conhecidos e incluem causas monogênicas (cerca de 20\% dos casos), cromossômicas (cerca de 25\%), que podem ser numéricas ou estruturais, e multifatoriais (cerca de $50 \%$ dos casos), que resultam da combinação de fatores genéticos (vários genes) e ambientais. Os de etiologia ambiental, responsáveis por efeitos disruptivos, são responsáveis por aproximadamente $5 \%$ dos casos e são os mais difíceis de serem estudados (Figura 1) (NUSSBAUM et al., 2007).

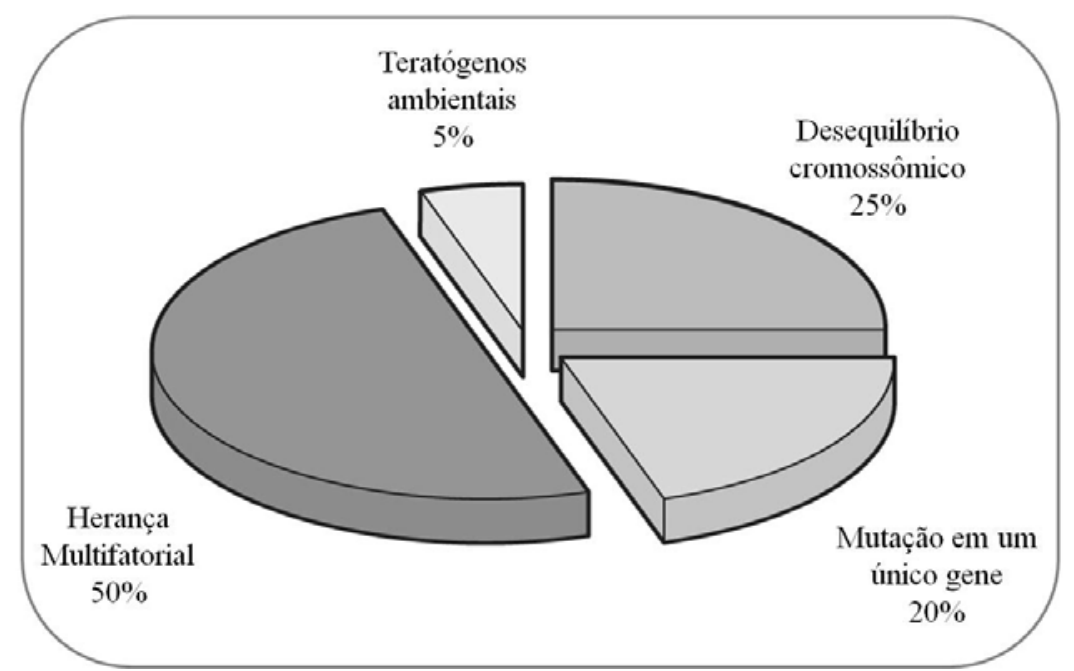

Figura 1.Frequências dos DC decorrentes de causa monogênica, cromossômica, multifatorial e ambiental. Adaptada de: NUSSBAUM et al., 2007. 
A idade materna e paterna avançadas, acima de 35 e 50 anos, respectivamente, constituem um fator de risco para o aparecimento dos DC. A idade materna avançada está relacionada ao risco de cromossomopatias numéricas na prole, como a trissomia do cromossomo 21, conhecida como síndrome de Down, que é a mais prevalente. Ao nascimento, a incidência desta síndrome em recém-nascidos de mulheres com idades entre 2530 anos é de cerca de 1:1.000; entre aquelas com 35 anos é de 1:385, chegando a 1:25 entre as de 45 anos ou mais. Entretanto, os fatores envolvidos na relação idade aumentada e nãodisjunção cromossômica ainda não estão esclarecidos (NUSSBAUM et al., 2007; MORRIS; SAVVA, 2008; SANTOS et al., 2009). Já a idade paterna, embora tenha sido sugerida também como um fator de risco para defeitos cromossômicos numéricos, não está confirmada, mas está comprovadamente relacionada ao aparecimento de síndromes gênicas específicas, entre as quais o Nanismo Acondroplásico (YANG et al., 2006; BAUJAT et al., 2008; GREEN et al., 2010).

A consanguinidade parental também é um fator de risco de doenças genéticas para a prole. Aumenta não apenas o risco de morbidade (para doenças autossômicas recessivas), de defeitos isolados e defeitos complexos, mas também de mortalidade pré e pós natal. Por exemplo, a união entre primos em primeiro grau aumenta em cerca de três vezes o risco de prole com malformações, comparado com o de casais não aparentados (TUNÇBILEK; ÖZGUÇ, 2007; AL-JARALLAH, 2009).

Os agentes teratogênicos, ou disruptivos, também são responsáveis pelo aparecimento de DC na prole. Teratógeno é qualquer agente, físico, químico ou biológico que pode causar aborto, anomalias congênitas, retardo do crescimento intra-uterino, retardo mental e até neoplasias. Por exemplo, a radiação ionizante, muitos medicamentos e toxinas são comprovadamente disruptivos. Enquanto algumas são conhecidas como altamente prejudiciais ao feto, como a Talidomida, que resulta principalmente em DC dos membros, e o álcool, que pode causar múltiplos defeitos, além de retardo intelectual e do crescimento, a maioria não tem seus efeitos sobre o embrião ou feto conhecidos (WANG et al., 2007; DE SANTIS et al., 2008; ORMOND et al., 2009; OTTAVIANI, 2009).

Alguns agentes infecciosos são notadamente deletérios à organogênese fetal. A rubéola é uma das infecções gestacionais de ação teratogênica mais acentuada. Quase que invariavelmente afeta o desenvolvimento embrionário e/ou fetal e pode resultar em lesões no sistema nervoso central, surdez, cegueira e cardiopatia. Entre outros que podem ser destacados estão o vírus da Imunodeficiência Humana Adquirida (HIV), do Herpes simplex, o citomegalovírus, o Treponema pallidum e o Toxoplasma gondii. (DI CARLO et al., 2008; 
MURPHY et al., 2008; VASQUEZ-MANZANILLA et al., 2008; ANZIVINO et al., 2009; GANDHOKE et al., 2009; IBIETA et al., 2009; MANDALA et al., 2009).

Diabetes mellitus gestacional (DMG) é um outro fator de risco para DC, especialmente cardíacos, do tubo neural e para a sequência da displasia caudal. Alguns estudos com modelos animais mostraram que o processo disruptivo da doença inclui alterações no perfil de expressão gênica do feto (PAVLINKOVA et al., 2009). DMG é definido como qualquer nível de intolerância a carboidratos, que resulta em hiperglicemia de gravidade variável, com início ou diagnóstico durante a gestação. Sua fisiopatologia é explicada pela elevação de hormônios contra-reguladores da insulina, pelo estresse físiológico imposto pela gravidez e por fatores predeterminantes, genéticos ou ambientais (METZGER et al., 2007; DODE; SANTOS, 2009).

A epilepsia é uma outra doença materna que pode interferir no desenvolvimento originalmente normal da criança. Afeta uma a cada 300 mulheres em idade fértil e confere risco moderado para microcefalia e retardo do crescimento intra-uterino. Os medicamentos anticonvulsivantes possuem ação teratogênica comprovada e representam um fator de risco adicional nestes casos, predispondo a fendas orofaciais, hipoplasia de falanges distais e defeitos do tubo neural (SMITH; WHITEHALL, 2009).

Há sugestões de que alimentação inadequada (carência nutricional) também pode aumentar o risco de DC. A nutrição deficiente, particularmente de ácido fólico, é um exemplo clássico, em que o risco de defeitos de fechamento do tubo neural é aumentado em fetos predispostos geneticamente. A suplementação periconcepcional e durante o primeiro trimestre de gravidez tem reduzido tanto o risco de ocorrência, como de recorrência para estes defeitos em 50 a 70\%, além de diminuir também o risco para defeitos cardíacos e de membros. Devido à gravidade e morbimortalidade relacionada a tais defeitos, é muito importante a suplementação dietética com esta vitamina e o Aconselhamento Genético das famílias de afetados (CARMICHAEL et al., 2007; SANTOS; PEREIRA, 2007; SAVITZ, 2008; SWEENEY et al., 2008; PACHECO et al., 2009).

\subsection{Patogenia}


Os DC correspondem a grupos heterogêneos de diagnósticos, cada qual com dismorfogênese distinta. Embora ainda se saiba pouco sobre os processos fundamentais que controlam a morfogênese humana normal (migração celular, controle mitogênico, interação tecidual, associação adesiva de células semelhantes, apoptose, ação hormonal e ação de forças mecânicas), as anomalias podem ocorrer de quatro mecanismos: malformação, deformação (deformidade), disrupção e displasia (TORIELLO, 2008).

Malformação é um termo utilizado quando um defeito morfológico de um órgão, parte dele ou região mais extensa do corpo está presente ao nascimento como resultante de um processo de desenvolvimento intrinsecamente anormal. Como consequência, as estruturas não serão ou serão formadas incompletamente ou indevidamente separadas. Estes defeitos comumente aparecem já nas oito semanas iniciais de gestação, no período da organogênese. Por exemplo, os indivíduos com distúrbios cromossômicos, como a síndrome de Patau e de Edwards, ou gênicos, como a síndrome de Apert e Fibrocondrogênese pertencem a esta categoria, ou seja, são malformados (CABRAL-OLIVEIRA et al., 2007).

Deformações ou deformidades são distorções nas estruturas fetais já formadas, secundárias à ação de forças mecânicas extrínsecas, como constrição uterina sobre o feto no canal de parto, ou intrínsecas, como edema fetal. Acomete mais cartilagens, ossos e articulações. Alguns casos de deslocamento congênito do quadril e pé-torto estão incluídos nesta categoria (NUSSBAUM et al., 2007).

As disrupções resultam de alterações que ocorrem em um desenvolvimento originalmente normal e provocam defeitos secundários. Como exemplos podem ser citadas as amputações de membros por ruptura do amnio causada pela introdução vaginal de objetos perfurantes e a ação do álcool sobre o embrião ou feto (síndrome do álcool fetal) (GOLDFARB et al., 2009; MESQUITA; SEGRE, 2009).

As displasias são alterações que ocorrem na histogênese (dishistogênese), que resultam em uma composição anormal dos tecidos, que podem adquirir até mesmo um aspecto tumoral. São descritas várias displasias ectodérmicas, como a Displasia Ectodérmica Anidrótica, e ósseas, como a Displasia Epifisária Múltipla (BONANNI, et al., 2007; JONES, 2007; TORIELLO, 2008).

\subsection{Aspectos Clínicos}


Os DC podem ser isolados ou fazerem parte de um padrão de defeitos maiores ou menores. Considerando-se os de fatores etiológicos conhecidos e os de origem desconhecida, são observados em 3 a 5\% dos recém-nascidos e na maioria das perdas gestacionais, de acordo com dados obtidos de diferentes populações mundiais (DE VIGAN et al., 2005; PINTO; NASCIMENTO, 2007; RAMOS et al., 2009). Estudos brasileiros são escassos e mostram frequências que variam entre 1,7 e 5\% (MOREIRA et al., 2001; CARVALHO et al., 2002; COSTA et al., 2006).

Como a classificação dos DC em subgrupos é complexa, a mais utilizada baseia-se na gravidade dos mesmos e os divide em maiores e menores. São considerados como maiores aqueles que resultam em comprometimento da saúde, requerem tratamento clínico ou cirúrgico, ou causam problemas estéticos e sociais. São responsáveis por taxas elevadas de mortalidade, doença e incapacidade física e/ou mental. Anencefalia, fenda labial ou palatina, hidrocefalia e cardiopatias são exemplos de DC maiores. Os DC menores, como a politelia, nevus pigmentares, micrognatia e clinodactilia, não requerem intervenção médica, embora possam em alguns indivíduos resultar em comprometimento estético. Servem como indicadores de problemas mais sérios, pois três ou mais anomalias menores podem significar a presença de síndromes malformativas (JONES, 2007; RAMOS et al., 2009).

Um indivíduo pode apresentar alterações múltiplas que ocorrem como parte de uma síndrome, sequência ou associação (complexo). Síndrome é definida como um conjunto de anormalidades congênitas que podem ser reconhecidas como um padrão e que resultam do mesmo fator etiológico específico. Sequência é o termo utilizado para indicar também um padrão de anormalidades, mas que ocorrem como eventos sequenciais derivados de uma alteração primária. A associação é reconhecida em casos nos quais ocorrem concomitantemente dois ou mais DC de forma não aleatória, contudo, sem etiologia conhecida ou presumida (CABRAL-OLIVEIRA et al., 2007).

Com raras exceções, o diagnóstico clínico de um padrão malformativo não pode ser realizado com base em um único defeito. Mesmo se for um evento raro, pode ser característico de várias síndromes de etiologias variadas. Um diagnóstico específico geralmente depende do reconhecimento do padrão global dos DC e a detecção de defeitos menores pode ser tão útil quanto a de maiores (JONES, 2007).

\subsection{Impacto dos defeitos congênitos}


A mortalidade infantil é um importante indicador de saúde de um país ou comunidade, por estar associada a fatores como saúde materna, qualidade e acesso a serviços de saúde, condições sócio-econômicas e práticas de saúde pública. Quando estratificadas as causas de mortalidade infantil, observa-se em várias regiões do mundo uma diminuição na taxa total de óbitos, em especial por causas infecciosas. Como resultante, a proporção de mortes atribuíveis aos DC vem aumentando (CHRISTIANSON; MODELL, 2004; WORLD HEALTH ORGANIZATION, 2004; HOROVITZ et al., 2005; MATHEWS; MACDORMAN, 2008).

Nos países desenvolvidos, como os Estados Unidos, os DC constituem a principal causa de morbimortalidade infantil. Tendência semelhante é observada no mundo em desenvolvimento. Em 20 dos 28 países da América Latina, os defeitos de nascimento constituem uma das dez primeiras causas de mortalidade infantil e ocupam do segundo ao quinto lugar entre as causas de disfunções em crianças menores de um ano, respondendo por 2 a 27\% da mortalidade nesta faixa etária (PENCHASZADEH, 2004; BRONBERG et al., 2009).

No Brasil, os DC passaram da quinta para a segunda causa dos óbitos em menores de um ano entre 1980 e 2000. À semelhança de outros países em desenvolvimento, nos últimos anos ocorreu uma diminuição substancial da taxa de mortalidade infantil em decorrência da melhora do saneamento básico, do controle de doenças infecto-contagiosas e do acesso maior das gestantes aos programas de exames pré-natais (HOROVITZ et al., 2006; CALONE, et al. 2009).

Em 1980, as causas perinatais eram responsáveis por 38\% dos óbitos em menores de um ano e as anomalias congênitas por apenas 5\%. Em 1990, o perfil começou a mudar. No ano de 2000, as causas infecciosas e respiratórias passaram para menos de $10 \%$ e as anomalias congênitas para $13 \%$ dos óbitos em crianças menores de um ano. Portanto, à medida que os problemas de origem infecto-contagiosa e carencial vão sendo resolvidos, os congênitos e hereditários se tornam mais relevantes para a saúde pública (MALTA et al., 2007; MARAM; UCHIMURA, 2008).

Em 2002, nos Estados Unidos, mais de $20 \%$ das mortes de recém-nascidos foram atribuídas a DC e outros $20 \%$ a complicações da prematuridade. Assim, aproximadamente metade das mortes de recém-nascidos pode ser atribuída aos transtornos no processo de desenvolvimento normal (NUSSBAUM et al., 2007).

Além da mortalidade, um outro fator relacionado às anomalias congênitas é a morbidade, definida como risco para o desenvolvimento de complicações clínicas, incluindo número de internações e gravidade das intercorrências, que limitam a produtividade do 
indivíduo. Os DC estão entre as causas que conduzem a anos potenciais de vida perdidos e são responsáveis por $75 \%$ dos defeitos físicos encontrados na população. As crianças afetadas têm probabilidade quatro vezes maior de não sobreviverem até o primeiro ano de vida (COLVIN; BOWER, 2009; GEREMIAS et al., 2009).

Outro problema é a cronicidade. O indivíduo com doença crônica necessita de tratamento contínuo, que implica em custos altos. DC diferentes têm prognósticos diferentes e geralmente os custos dos tratamentos médicos necessários são altos. Alguns são corrigidos cirurgicamente no início da vida e curados, enquanto outros requerem tratamento médico constante, muitas vezes para o resto da vida. A estimativa de custo-vida médio por criança deve considerar, inclusive, a necessidade de estimulação precoce do desenvolvimento (geralmente com Fisioterapia, Fonoaudiologia e Terapia Ocupacional), educação especial ou inclusiva, perda da produtividade por incapacidade ou morte e a diminuição da renda salarial familiar do responsável pelos cuidados da criança. A este cálculo devem ser adicionados os custos psicossociais, como trauma psicológico da família e as dificuldades de adaptação à sociedade "normal", com grande risco de desestruturação familiar (HOROVITZ et al., 2005; MAZER et al., 2008).

Os recém-nascidos com DC maiores geralmente apresentam baixo peso e necessitam de hospitalizações prolongadas, com acompanhamento especializado por períodos longos de tempo. Nascem geralmente de partos prematuros e cesareanas, que se somam aos diversos recursos médicos e não médicos necessários. Estima-se que crianças com DC representam até 30\% de todas hospitalizações pediátricas (THONG et al., 2005; CASE; CANFIELD, 2009; COLVIN; BOWER, 2009). Não foram encontrados dados brasileiros sobre o impacto econômico destes defeitos na sociedade ou sobre os custos diretos e indiretos referentes ao tempo de vida dos afetados.

\subsection{Prevenção}

A prevalência dos DC muitas vezes é alta devido à falta de compreensão dos mecanismos patogênicos. A esta dificuldade se somam a ausência de políticas públicas de saúde eficazes que envolvam redução da fertilidade, imunização contra doenças infectocontagiosas maternas que afetam o concepto, planejamento familiar, cuidados préconcepcionais e pré-natais, suplementação vitamínica e realização de diagnóstico pré-natal (GUILAN; CORRÊA, 2007; IONESCU-ITTU et al., 2009). 
As informações sobre os DC tornam-se cada vez mais relevantes em todo mundo porque a partir delas podem ser planejadas ações de prevenção nos três níveis, primário, secundário e terciário (HOROVITZ et al., 2005, HANSEN et al., 2009).

A prevenção primária é realizada antes da concepção, a fim de evitar a ocorrência do defeito, como a suplementação vitamínica com ácido fólico. A prevenção secundária é feita durante o período da gestação e pode, por exemplo, permitir diagnósticos e tratamentos precoces, enquanto a prevenção terciária é pós-natal e consiste na assistência aos afetados e suas famílias, com objetivo de minimizar danos (reabilitações médicas, psicológicas e sociais). Para estabelecer medidas preventivas é importante a identificação de indivíduos em risco (obtenção da história familial) e a realização de testes de triagem (clínico, bioquímico, para portador de gene recessivo, etc) (CABRAL-OLIVEIRA et al., 2007; SAVITZ, 2008).

$\mathrm{O}$ diagnóstico preciso dos $\mathrm{DC}$ também é um pré-requisito necessário para o prognóstico e elaboração de planos de conduta para o paciente, assim como para o Aconselhamento Genético da família. Este último permite a prevenção primária, secundária e terciária dos DC (LIN et al., 2009).

No Brasil, os dados epidemiológicos oficiais referentes às anomalias congênitas são escassos e incompletos, como referido anteriormente, e o país não dispõe de um sistema de informação de base populacional específico sobre DC para monitorar a sua prevalência, o que indica a necessidade urgente do aprimoramento dos sistemas de informação existentes. Mesmo o Estudo Colaborativo Latino Americano de Malformações Congênitas (ECLAMC) oferece poucas informações, pois o número de instituições brasileiras que colaboram com o mesmo é reduzido (GUERRA et al., 2008; GEREMIAS et al., 2009).

O registro provisório de nascimento de crianças brasileiras, Declaração de Nascido Vivo, dispõe de um campo que deve ser preenchido por profissionais da saúde, denominado Campo 34, em que deve ser informada presença de alguma malformação congênita e/ou anomalia cromossômica (Sim/Não/Ignorado/Qual?). Segundo Geremias et al. (2009), entretanto, nem sempre o preenchimento deste campo é realizado, mas a proporção de ignorados ou em branco diminuiu deste a sua implantação.

No município de São José do Rio Preto (SP) o número de crianças que nascem ou vão a óbito por DC é desconhecido. O maior hospital da cidade, o Hospital de Base de São José do Rio Preto (HB), cobre uma região de 99 municípios onde se concentram cerca de um milhão e meio de habitantes. Administrado pela Fundação Faculdade Regional de Medicina de São José do Rio Preto (FUNFARME), uma entidade privada, é um dos maiores do interior do Estado de São Paulo, com um complexo médico-assistencial e hospitalar indispensável 
para o atendimento à população (FACULDADE DE MEDICINA DE SÃO JOSÉ DO RIO PRETO, 2009). No HB também não há registros oficiais do número de nascimentos com DC. Também não foram encontrados registros publicados de outros hospitais do município.

A identificação de DC em São José do Rio Preto pode ser utilizada para o esclarecimento de fatores epidemiológicos importantes, estabelecimento de estratégias de prevenção nos três níveis e Aconselhamento Genético adequado para as famílias envolvidas, além de aprimorar o atendimento dos profissionais de maternidades.

A hipótese científica que foi testada neste estudo é que a frequência de DC nos recémnascidos e natimortos atendidos no $\mathrm{HB}$ é alta, envolve várias etiologias e fatores de risco, com consequências graves, e pode ser representativa da realidade do município e região. 


\section{OBJETIVOS}

\subsection{Objetivo Geral}

Realizar um estudo genético clínico prospectivo de todos os recém-nascidos e natimortos com defeitos congênitos, atendidos em um período de um ano no Hospital de Base de São José do Rio Preto/SP, para avaliação da prevalência de anomalias congênitas, suas possíveis causas e consequências.

\subsection{Objetivos Específicos}

1. Estimar a prevalência de defeitos congênitos ocorridos no período de um ano no Hospital de Base de São José do Rio Preto/ SP;

2. Classificar os defeitos congênitos encontrados na busca de possíveis diagnósticos;

3. Pesquisar possíveis causas envolvidas no aparecimento dos defeitos (ambientais, gênicas, cromossômicas ou multifatoriais);

4. Avaliar algumas consequências destes defeitos, como taxa de óbito e período de hospitalização dos afetados;

5. Analisar o preenchimento do Campo 34 da Declaração de Nascido Vivo;

6. Auxiliar no fornecimento de subsídios para o Aconselhamento Genético das famílias dos afetados e elaboração de estratégias preventivas por parte dos órgãos competentes. 


\section{MATERIAL E MÉTODOS}

\subsection{Casuística}

Após aprovação do Comitê de Ética em Pesquisa (CEP - Parecer número 341/2008), da Comissão Nacional de Ética em Pesquisa (CONEP) e obtenção do Termo de Consentimento Livre e Esclarecido (TCLE) (Anexo A) foram estudados, de maneira prospectiva, no período de $1^{\circ}$ agosto de 2008 a 31 julho de 2009, indivíduos com DC, recémnascidos (até 28 dias de vida) e natimortos, atendidos no Hospital de Base de São José do Rio Preto, SP (FAMERP/FUNFARME).

Para realização deste estudo, as estratégias utilizadas incluíram: 1) o contato pessoal e por meio de reuniões com os profissionais da Pediatria, Ginecologia e Obstetrícia, para esclarecimentos sobre o projeto e seus objetivos; 2) colocação de pequeno cartaz com a frase "Casos de defeitos congênitos maiores ou menores, favor contatar Dra. Agnes Conte ou Camila Ive pelos ramais 1931/1932 ou telefone celular, Gratos" nos diferentes setores que prestam atendimento a recém-nascidos; 3) participação das reuniões do Centro Interdepartamental de Medicina Fetal (CIMEFE/FAMERP) e 4) visitas diárias nos setores de Ginecologia e Obstetrícia (alojamento conjunto), UTI Neonatal, UTI Cardiológica Pediátrica e Enfermaria da Pediatria. Portanto, as avaliações foram realizadas a partir da solicitação verbal e atendimento às solicitações de pareceres encaminhados pelos médicos ao Serviço de Genética.

A mãe e/ou o pai do concepto foram convidados a participar do estudo após o parto, em momento adequado, conforme orientação da equipe de saúde e disponibilidade dos mesmos. Nenhum responsável se recusou participar do estudo, porém a permissão para obtenção de fotografias foi negada em dois casos.

Foi realizado registro fotográfico, exame físico detalhado, que incluiu a identificação das características de nascença e medidas do corpo. Esta etapa contou com a colaboração dos geneticistas, pediatras e obstetras do próprio HB.

Os dados epidemiológicos, clínicos e de exames realizados foram obtidos dos prontuários médicos e de uma entrevista com o pai e/ou a mãe para coleta de informações 
adicionais (história obstetrícia prévia, da gestação do paciente, antecedentes pessoais e familiais).

Nos casos indicados para confirmação ou investigação de cromossomopatias, foi coletada uma amostra de sangue periférico ou de cordão umbilical para estudo cariotípico. Esta parte do estudo contou com a colaboração da bióloga Valéria Cristina Carvalho Ferrarese (Laboratório de Genética FAMERP/FUNFARME).

\subsection{Métodos}

\subsubsection{Avaliação Genético-Clínica}

Todos os indivíduos receberam um código de identificação para proteção da privacidade dos mesmos.

A entrevista com a mãe e/ou o pai incluiu a investigação de dados como presença ou ausência de malformações na família, história obstétrica, exposição a agentes disruptivos, entre outros, conforme protocolo apresentado no Anexo B. Alguns dados foram obtidos da entrevista, enquanto outros foram obtidos do prontuário médico e de informações fornecidas pelo CIMEFE/FAMERP e por neonatologistas.

Foram estudadas características e medidas físicas, sempre pela mesma equipe, composta entre outros, por um geneticista e um médico pediatra, de acordo com o protocolo padrão utilizado no Serviço de Genética, desenvolvido rotineiramente no referido Hospital.

As alterações físicas e os desvios do padrão de normalidade foram considerados de acordo com os critérios descritos por Jones (2007). Os valores normais esperados para um indivíduo foram obtidos utilizando-se curvas de normalidade, construídas a partir de valores observados em grandes grupos amostrais tomados ao acaso, respeitando-se sexo e idade. Todo valor que superou dois desvios padrões da curva média foi tido como anormal pelo fato deste intervalo de confiança incluir $98 \%$ do universo populacional. Neste estudo foram considerados percentis menores que $2 \%$ e maiores que $98 \%$ como desviantes.

Cada caso foi estudado detalhadamente em busca do diagnóstico etiológico. Naqueles em que isso não foi possível, foram consideradas duas categorias: defeitos múltiplos ou defeitos aditivos randômicos. 
Como "defeitos múltiplos" foi considerada qualquer combinação de dois ou mais defeitos maiores para os quais nenhum fator etiológico foi demonstrado ou suspeito. "Defeitos aditivos randômicos" foi uma categoria considerada em casos de combinação de dois ou mais defeitos maiores com clara evidência de fatores etiológicos não relacionados (WORLD HEALTH ORGANIZATION, 2006a; WORLD HEALTH ORGANIZATION, 2006b).

Após o estudo realizado pela equipe envolvida diretamente com o projeto, todos os casos foram novamente discutidos com o Prof. Dr. Antônio Richieri da Costa (USP-Bauru).

Os dados obtidos foram analisados de forma descritiva. Para as variáveis quantitativas foi realizado o cálculo de medidas de tendência central (média) e de dispersão (desvio padrão); para as variáveis qualitativas foram calculadas as suas frequências.

Quanto à interpretação do preenchimento do Campo 34 da Declaração de Nascido Vivo, este foi aqui denominado correto quando pelo menos a presença de DC foi observada e assinalada como "sim", independente do diagnóstico ou defeito estarem caracterizados, e como incorreto quando o defeito era possível de ser detectado em avaliação clínica e o campo foi preenchido como "não".

\subsubsection{Cultura de Linfócitos e Bandamento GTG}

Nos casos indicados para estudo citogenético foram utilizadas metáfases obtidas de culturas de linfócitos de sangue periférico realizadas a partir da coleta, com seringa estéril descartável, por profissional qualificado (enfermeiro), de 1-3ml de sangue venoso periférico ou de cordão umbilical. Tais culturas foram mantidas por 72 horas e seguiram os procedimentos descritos por Moorhead et al. (1960), com modificações, de acordo com o protocolo padrão utilizado pelo Laboratório de Genética da FAMERP/FUNFARME.

Para cada indivíduo foram montados três frascos de cultura contendo $1-3 \mathrm{ml}$ de sangue, $5 \mathrm{ml}$ de meio de cultura RPMI 1640, suplementado com 20\% de soro fetal bovino, penicilina (100U/ml) e fito-hemaglutinina (PHA-Gibco-0,2ml). Para interrupção da divisão celular foi adicionado $0,1 \mathrm{ml}$ de solução de colquicina a $4 \times 10 \mathrm{M}$ a cada frasco, 30 minutos antes da colheita da cultura. Após o bloqueio celular, o material foi centrifugado, o sedimento hipotonizado com $\mathrm{KCl}$ a $0,075 \mathrm{M}$ por 10 minutos, a $37^{\circ} \mathrm{C}$, e fixado em metanol: ácido acético 
(3:1). A suspensão celular foi gotejada em lâminas limpas, molhadas e geladas. Após sofrerem "envelhecimento" natural por cerca de três dias ou em estufa a $90^{\circ} \mathrm{C}$ por 20 minutos, foram submetidas ao bandamento GTG, segundo a técnica de Grouchy e Turleau (1977), com modificações, ou a outras técnicas complementares, de acordo com a necessidade.

Cada caso foi identificado durante toda a execução do projeto por um código do conhecimento das responsáveis pela pesquisa. A análise do cariótipo foi realizada em 20 metáfases submetidas ao bandamento GTG. Os achados e a descrição dos mesmos foram apresentados de acordo com os critérios contidos na International System for Human Cytogenetic Nomenclature (2009).

Cada resultado foi entregue diretamente à família, em sessão de Aconselhamento Genético previamente agendada pelo geneticista, realizada no Ambulatório de Genética. 


\section{RESULTADOS}

A ausência de alguns dados dos casos estudados foi consequência de fatores, tais como: abandono da criança no leito hospitalar, do fato da família desconhecer ou não poder ser contatada para fornecer informações adicionais, do hospital de origem não ter registros sobre determinadas ocorrências ou se recusar a fornecer informações, e da evolução para óbito antes da realização de exames complementares.

\subsection{Prevalência}

Foram identificados e estudados 110 indivíduos portadores de DC atendidos no HB. Destes, 103 (94\%) eram recém-nascidos (RN) e 07 (6\%) natimortos (NT), 61 (55\%) do sexo masculino, 47 (43\%) do sexo feminino (razão de 1,3:1) e dois (2\%) de sexo indeterminado, 101 (92\%) caucasóides ou orientais e nove (8\%) negróides. Do total de atendidos, 85 (77\%) nasceram no HB e 25 (23\%) nasceram em outros locais e foram encaminhados ao mesmo. Dos nascimentos, $99 \%$ ocorreram em hospitais e 1\% no domicílio.

Para estimativa da prevalência de DC na população estudada, uma vez que esta depende do conhecimento do total de nascimentos em um determinado período de tempo, foram considerados apenas os indivíduos nascidos no $\mathrm{HB}$ e não todos os atendidos. No período do estudo foram realizados 3.026 partos, portanto, a prevalência de DC foi de 2,8\%.

\subsection{Variáveis Maternas, Paternas e Características Obstétricas de Importância Perinatal}

A idade materna dos indivíduos com DC variou de 13 a 46 anos. A maioria (63\%) das mães tinha idades entre 20 e 34 anos, $21 \%$ apresentavam idades de 13 a 19 anos e $14 \%$ acima de 35, com média de 26 anos e desvio padrão de 7,09 (Gráfico 1). 


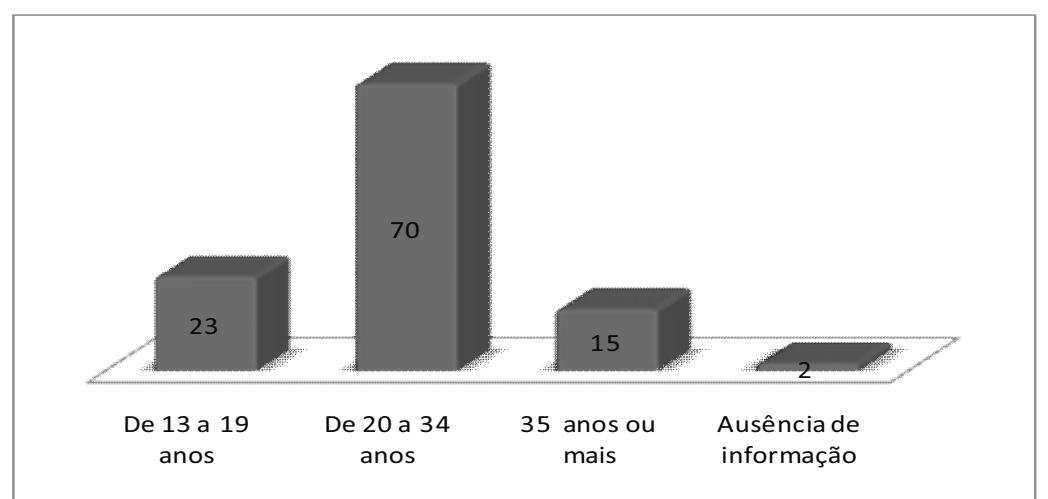

Gráfico 1. Distribuição da idade materna na população estudada.

Com relação ao número de gestações, 51 (46\%) das gestantes eram primigestas (Gráfico 2). Aborto espontâneo anterior foi referido por 16 (15\%) das mães. Cinco (4,5\%) gestantes não realizaram o seguimento pré-natal.

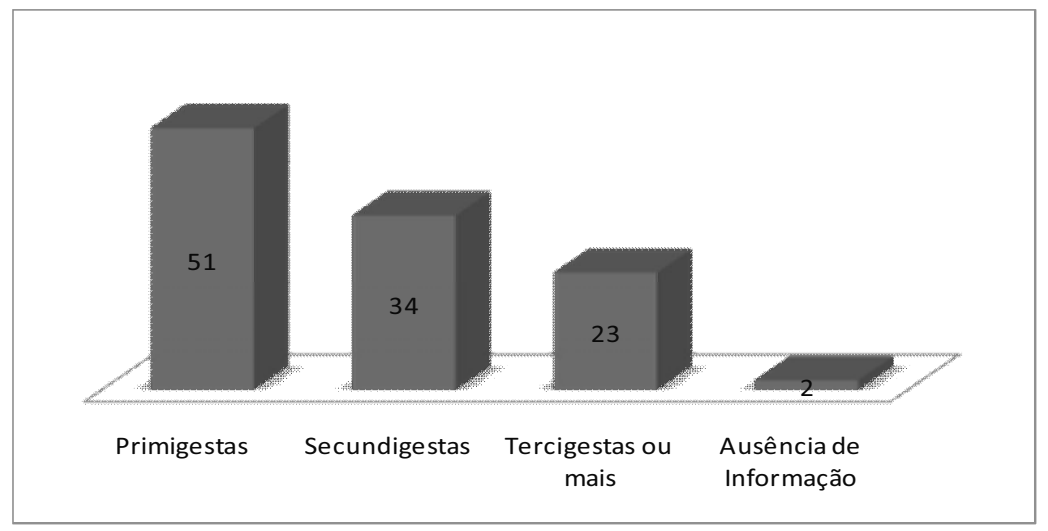

Gráfico 2. Mães por número de gestações.

Alterações do volume do líquido amniótico ocorreram em 13\% das gestações, sendo oligodrâmnio em $10 \%$ e polidrâmnio em 3\%. O diabetes gestacional foi detectado em $7 \%$ das mães e duas delas $(1,8 \%)$ eram obesas mórbidas. Das mães, $13 \%$ relataram ingestão excessiva de bebidas alcoólicas (várias doses em vários dias da semana) e 15\% tabagismo e/ou uso de drogas ilícitas durante a gestação.

União consanguínea foi observada em dois casos $(1,8 \%)$. No primeiro os pais da criança eram primos em primeiro grau e o recém-nascido nasceu com defeitos associados: cardiopatia, pregas epicânticas, orelhas displásicas, alterações costais, politelia, hipertelorismo mamário, polidactilia pós-axial em mão esquerda, sindactilia entre $4^{\circ}$ e $5^{\circ}$ pododáctilos do pé esquerdo, luxação congênita de joelhos, insuficiência renal aguda e fístula anal, entre outros 
(Figura 2). Embora de etiologia provavelmente genética, autossômica recessiva, o diagnóstico não foi possível. No segundo caso, os pais eram primos em $2^{\circ}$ grau e a criança nasceu com Distrofia Torácica de Jeune (OMIM 208500) (Figuras 3a e b).

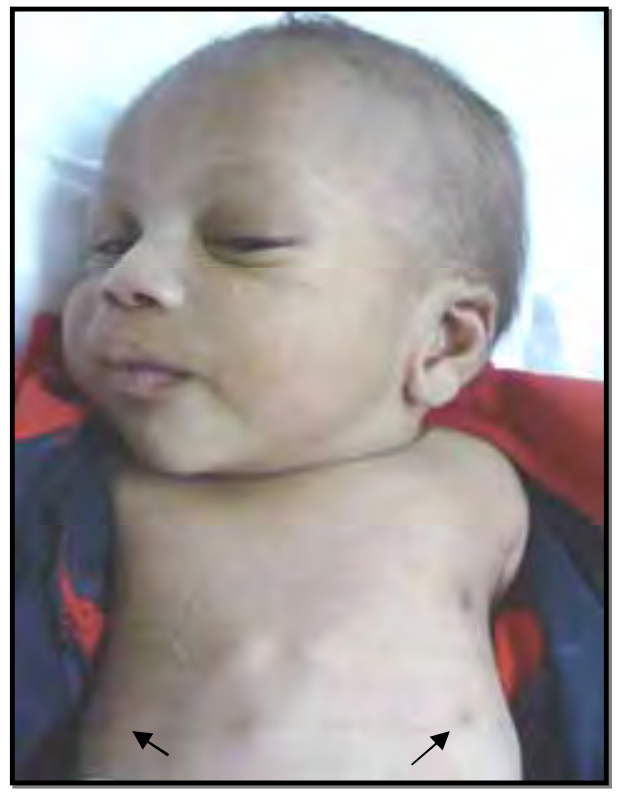

Figura 2. Paciente com defeitos associados, com destaque para politelia bilateral.

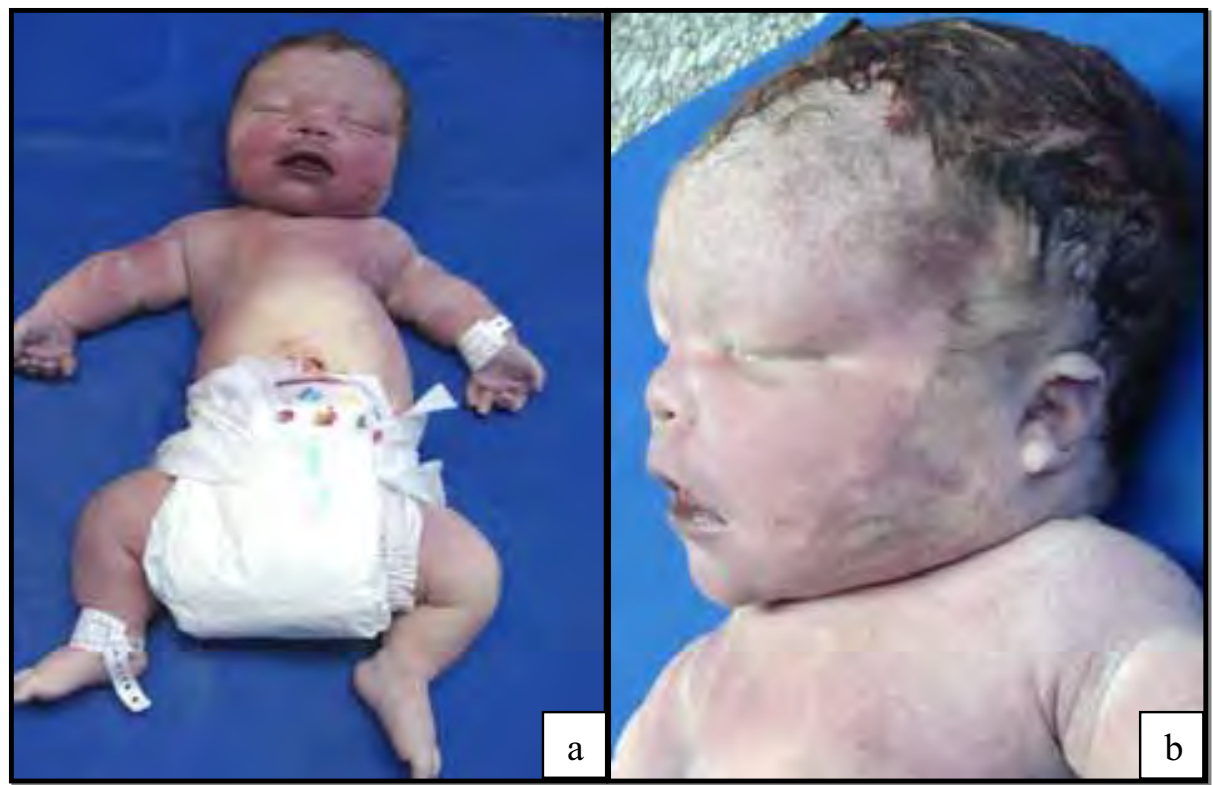

Figura 3. Paciente com Displasia Torácica de Jeune - corpo inteiro(a) e face (b). 
A idade paterna variou de 17 a 51 anos (média de 29 anos e desvio padrão de 7,52). Apenas um pai tinha mais de 50 .

Não foi possível obter a idade de alguns pais ou por eles serem desconhecidos (paternidade desconhecida ou não assumida) ou pelo fato das mães desconhecerem a data de nascimento dos mesmos.

\subsection{Variáveis Perinatais}

A Tabela 1 apresenta algumas variáveis perinatais estudadas.

Entre os casos atendidos, quanto à idade gestacional, 65\% eram prematuros e $35 \%$ nasceram a termo. O período médio das gestações foi de 35 semanas, que variou de 25 a 41 semanas. A maioria (77\%) nasceu de parto cesárea.

$\mathrm{O}$ valor do Apgar de $1^{\circ}$ minuto e de $5^{\circ}$ minuto foi normal na maioria dos casos.

Dos indivíduos observados, $52 \%$ apresentaram peso baixo ao nascimento, ou seja, menor que 2.500 gramas (g). O peso médio dos $\mathrm{RN}$ foi de $2.393 \mathrm{~g}$, com máximo de $4.120 \mathrm{~g}$ e mínimo de $460 \mathrm{~g}$, e desvio padrão de $859 \mathrm{~g}$.

A estatura ao nascimento foi obtida em apenas $57 \%$ da casuística, e isso ocorreu devido ao desconhecimento desse dado pela família e ausência dessa informação no prontuário médico. A média foi de 44 centímetros $(\mathrm{cm})$, desvio padrão de $5,68 \mathrm{~cm}$ e variou de 28 a $52 \mathrm{~cm}$. Em 49\% dos RN estudados a baixa estatura esteve presente.

Cento e quatro (95\%) gestações eram de concepto único e seis $(5 \%)$ eram gemelares, duas monozigóticas, duas dizigóticas e duas de zigozidade não esclarecida.

O período médio de internação foi de 33 dias. O maior período foi de 254 dias em um caso de gastrosquise com complicações cirúrgicas. A coleta dos dados terminou em 31 de julho de 2009 e até janeiro de 2010 um indivíduo ainda continuava hospitalizado.

A evolução para óbito no período de hospitalização foi observada em 35 (32\%) casos. Destes, 25 foram óbitos neonatais, ou seja, que ocorreram em crianças menores de 28 dias. No período estudado, no HB foram registrados 40 casos de óbito no período neonatal e $62 \%$ deles ocorreram em RN com DC. 
Tabela 1. Frequências de casos de acordo com as variáveis estudadas.

\begin{tabular}{ll}
\hline \multicolumn{1}{c}{ Variável } & $\begin{array}{c}\text { Frequência de } \\
\text { indivíduos } \\
\end{array}$ \\
& $\mathbf{N}^{\circ} / \%$ \\
\hline Idade gestacional inferior a 37 semanas & $72(65)$ \\
Idade gestacional $\geq 37$ semanas & $38(35)$ \\
Parto normal & $25(23)$ \\
Parto cesárea & $85(77)$ \\
Apgar 0-3 no $1^{\circ}$ minuto: & $16(15)$ \\
Apgar 4-7 no $1^{\circ}$ minuto: & $29(26)$ \\
Apgar 8-10 no $1^{\circ}$ minuto: & $55(50)$ \\
Ausência de informação sobre apgar & $10(09)$ \\
Apgar 0-3 no $5^{\circ}$ minuto: & $10(09)$ \\
Apgar 4-7 no $5^{\circ}$ minuto: & $10(09)$ \\
Apgar 8-10 no $5^{\circ}$ minuto: & $80(73)$ \\
Ausência de informação sobre apgar & $10(09)$ \\
Baixo peso $(<2.500 \mathrm{~g})$ & $57(52)$ \\
Peso normal $\geq 2.500 \mathrm{~g})$ & $53(48)$ \\
\hline
\end{tabular}

\subsection{Recorrência Familial do Defeito Congênito}

Em três casos (3\%) o defeito na criança era recorrente, com um genitor afetado. Um apresentava fenda orofacial (lábio e palato - Figura 4) e mãe também afetada. Outro tinha hipocondroplasia (Figura 5), cuja mãe possuía o mesmo fenótipo, e o terceiro, politelia (Figura 6) de herança paterna.

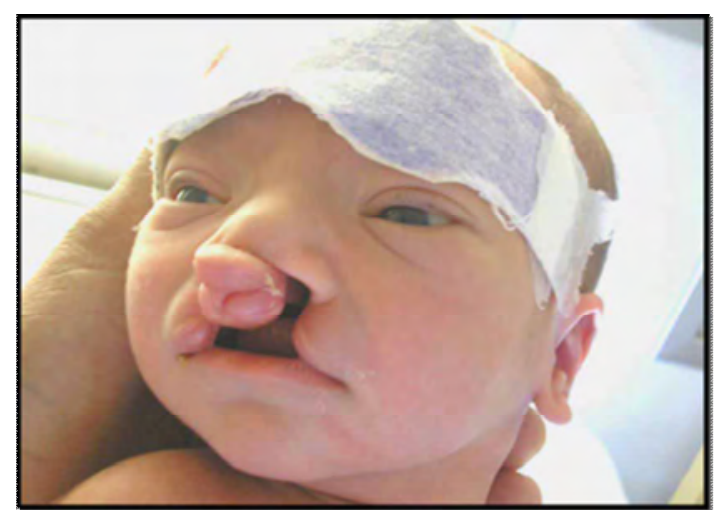

Figura 4. Paciente com fissura labial e palatina. 


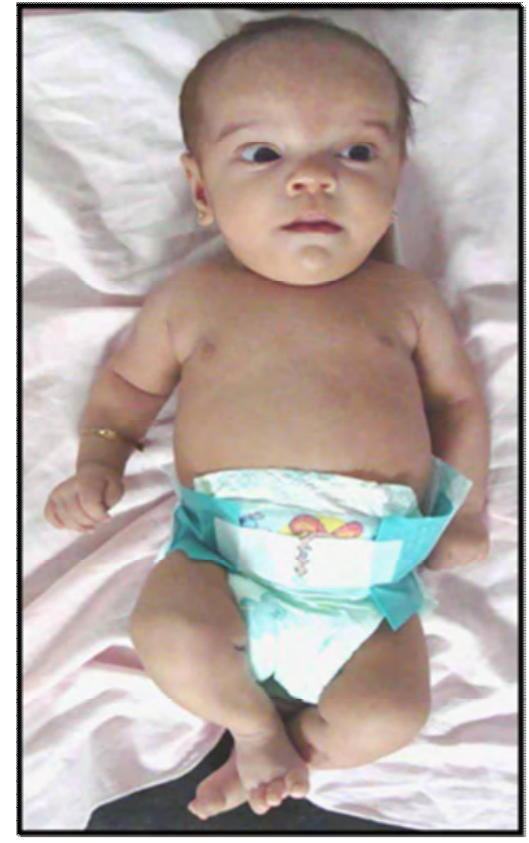

Figura 5. Paciente com Hipocondroplasia, com destaque para redução do tamanho dos membros.

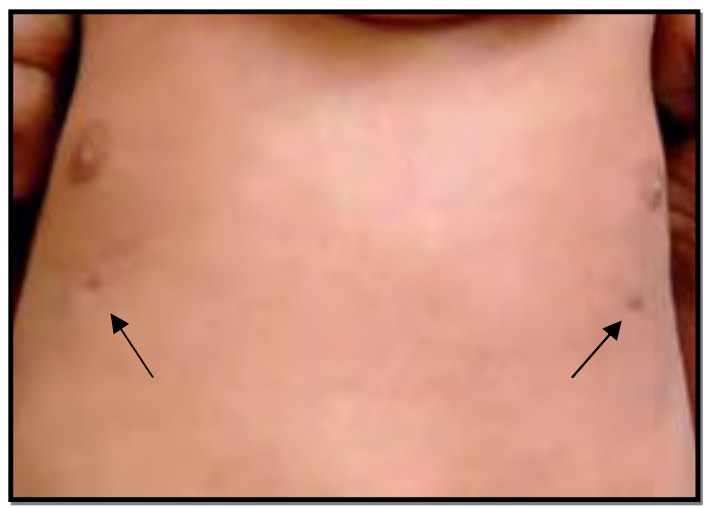

Figura 6. Paciente com politelia bilateral indicada pelas setas.

Em cinco $(4,5 \%)$ casos ocorreu malformação em conceptos de gestações anteriores. Em três casos a recorrência foi do mesmo defeito congênito: cardiopatia congênita em dois casos e mielomeningocele em um. 


\subsection{Análise Cariotípica}

O exame do cariótipo foi realizado em 60 casos indicados. Outros que estavam indicados não puderam ser realizados por óbito intra uterino e impossibilidade de coleta. Em 50 os resultados foram obtidos e a maioria (37-74\%) apresentou cariótipo normal. A prevalência de anormalidades foi de $26 \%$ e todos apresentaram alterações numéricas. Todas as alterações cromossômicas envolveram autossomos (Tabela 2).

Em 10 (17\%) não houve crescimento celular e o exame não pode ser repetido. Tais ocorrências puderam ser parcialmente justificadas pelo envio tardio do material de cordão umbilical ao Laboratório de Genética, armazenamento inadequado de amostras nos setores hospitalares, não retorno das famílias após convocação para nova coleta e óbito da criança antes da repetição do exame.

Tabela 2. Distribuição segundo êxito das culturas celulares para análise citogenética dos cariótipos realizados.

\begin{tabular}{ccc}
\hline Exame/Resultados & N & \% \\
\hline Cariótipo & 60 & 100 \\
Com crescimento & 50 & 83 \\
Sem crescimento & 10 & 17 \\
Normais & 37 & 74 \\
Alterados & 13 & 26 \\
Alterações numéricas & 13 & 100 \\
\hline
\end{tabular}

Entre os alterados, o achado mais frequente foi a trissomia do cromossomo 21, compatível com a síndrome de Down (69\%) (Figura 7a-f), seguido pela trissomia do 18, da síndrome de Edwards (23\%) (Figura 8a-c) e da trissomia do 13, compatível com a síndrome de Patau (8\%) (Figura 9a-c). 


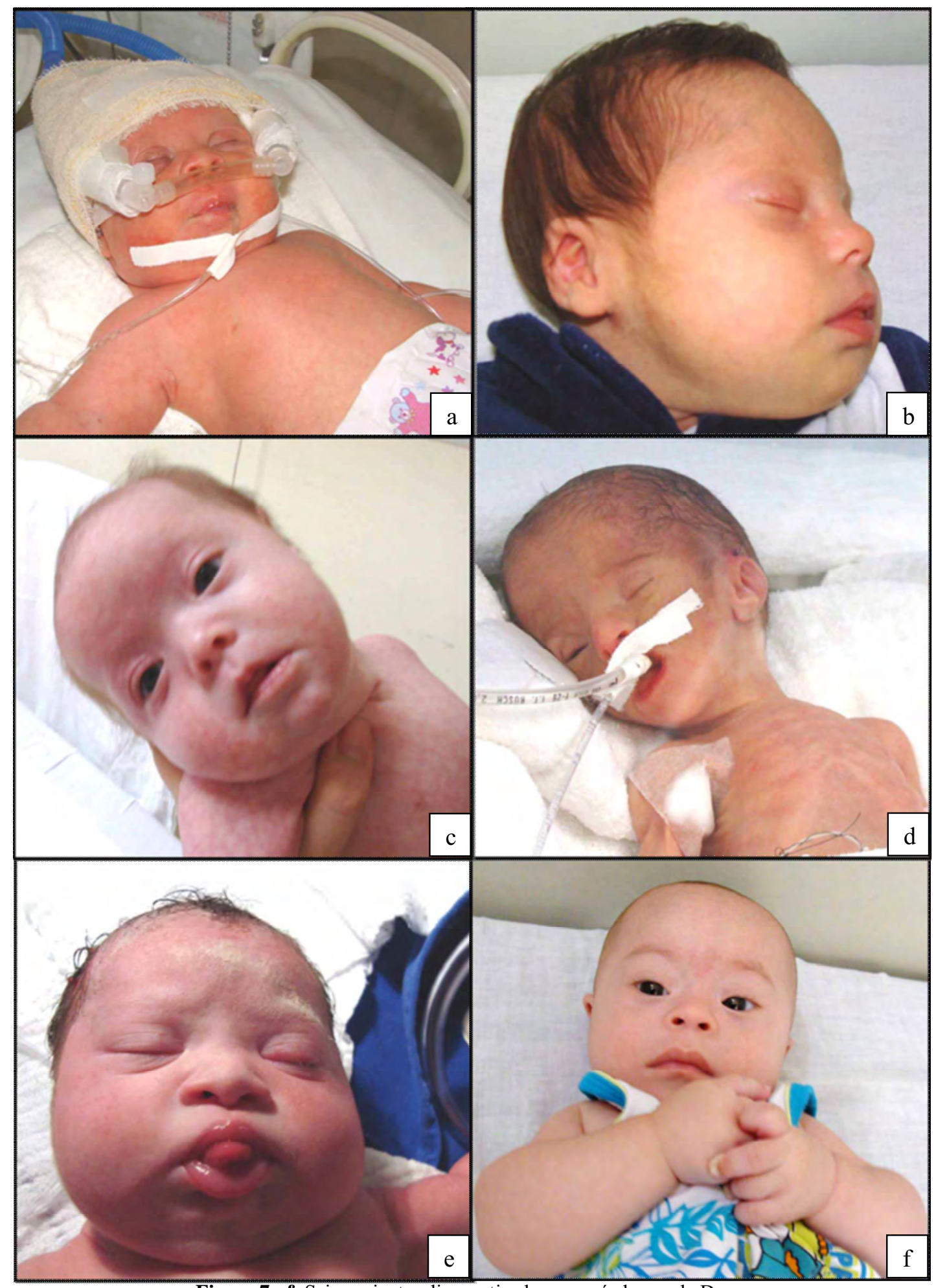

Figura 7a-f. Seis pacientes diagnosticados com síndrome de Down. 


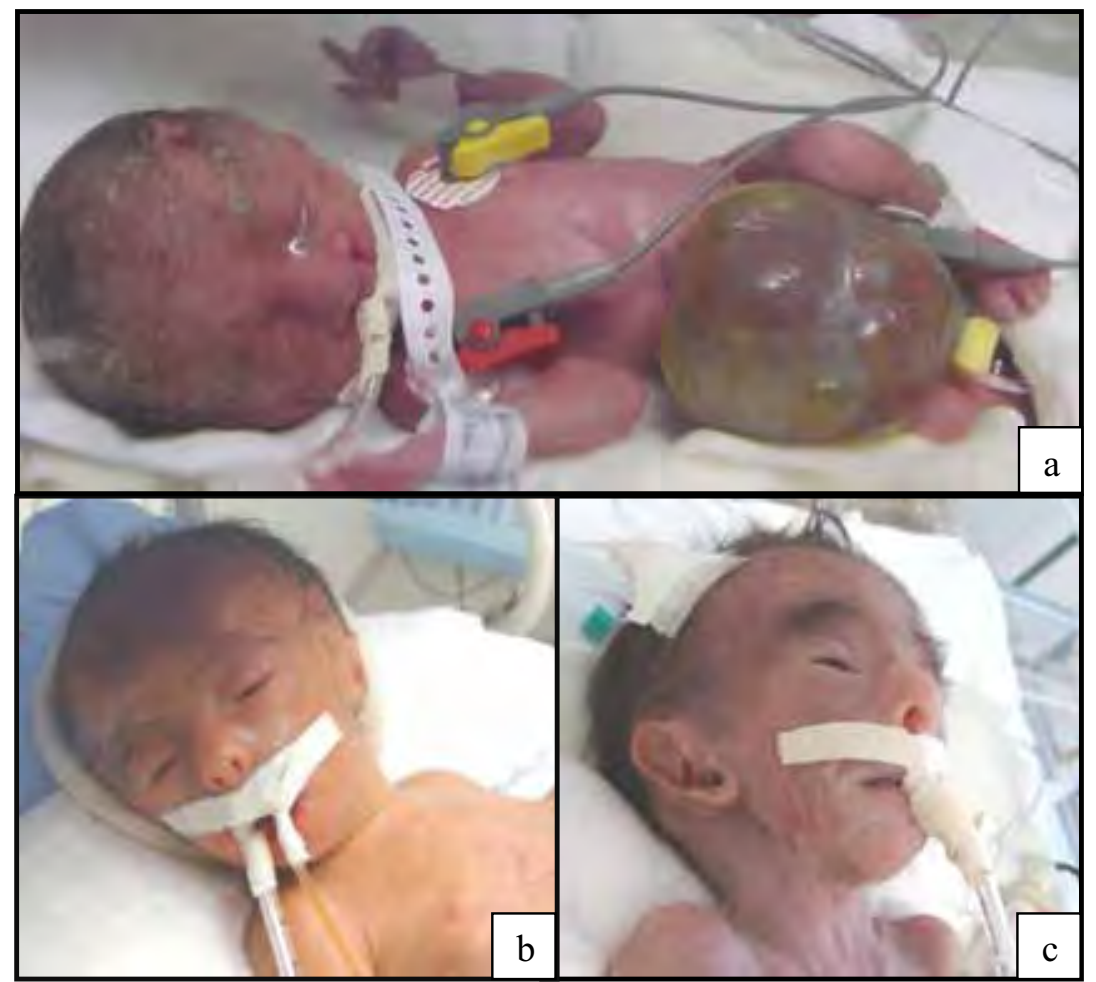

Figura 8a-c. Três pacientes com síndrome de Edwards.

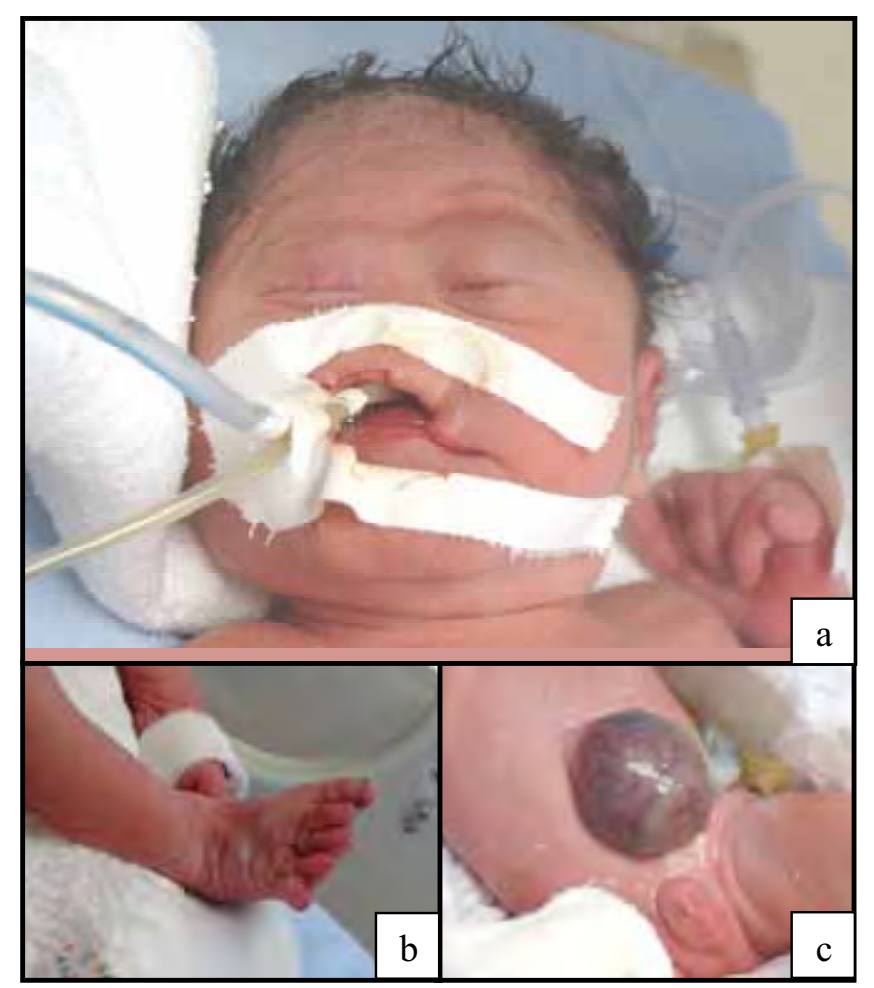

Figura 9. Paciente diagnosticado com síndrome de Patau. Aspecto facial (a), polidactilia (b) e onfalocele (c). 


\subsection{Defeitos Congênitos Encontrados}

O diagnóstico conclusivo dos DC isolados ou de afecções complexas foi possível em 89 casos (81\%). Em seis (5\%) o diagnóstico pode ser presumido e em 15 (14\%) era desconhecido (defeitos múltiplos). Nenhum caso apresentou defeitos aditivos randômicos (Tabela 3). O Gráfico 3 apresenta todos os casos por diagnóstico.

As Figuras 10 e 11 apresentam pacientes com alguns tipos de DC com diagnóstico concluído, a Figura 12 alguns daqueles com possível diagnóstico (presumido) e a Figura 13 alguns pacientes com defeitos múltiplos sem diagnóstico conclusivo ou presumido. 
Tabela 3. DC com diagnósticos concluídos, presumidos(*) e desconhecidos (defeitos múltiplos - **), com etiologia de acordo com dados obtidos da literatura .

\begin{tabular}{|c|c|c|}
\hline Hipótese Diagnóstica & $N^{0}$ de casos & Etiologia \\
\hline Anomalia Anorretal (OMIM 107100) & 1 & Monogênica \\
\hline Ânus Imperfurado & 1 & Heterogênea \\
\hline Aplasia Congênita de Cútis (OMIM 107600) & 1 & Monogênica \\
\hline Associação VATERR & 1 & Desconhecida \\
\hline Associação VATERR* & 1 & Desconhecida \\
\hline Atelosteogênese Tipo III (OMIM 108721)* & 1 & Monogênica \\
\hline Atresia de Esôfago & 2 & Multifatorial \\
\hline Atresia de Vias Biliares Extra-Hepáticas (OMIM 210500) & 1 & Desconhecida \\
\hline Atresia intestinal & 1 & Desconhecida \\
\hline Campodactilia (OMIM 114200) & 1 & Monogênica \\
\hline Cardiopatia Congênita & 9 & Multifatorial \\
\hline Colpocefalia & 1 & Heterogênea \\
\hline Complexo Membro Parede & 1 & Heterogênea \\
\hline Defeitos Múltiplos** & 15 & Heterogênea \\
\hline DFTN & 7 & Multifatorial \\
\hline Displasia Campomélica (OMIM 114290) & 1 & Monogênica \\
\hline Displasia Tanatofórica Tipo II (OMIM 187601) & 1 & Monogênica \\
\hline Disrupção por Diabetes & 3 & Ambiental \\
\hline Distrofia Torácica de Jeune (OMIM 208500) & 1 & Monogênica \\
\hline Divertículo de Meckel (OMIM 155140) & 1 & Monogênica \\
\hline Doença autossômica recessiva* & 1 & Monogênica \\
\hline Espectro Óculo-Aurículo-Vertebral & 1 & Desconhecida \\
\hline Fenda Labial e/ou Palatina & 3 & Heterogênea \\
\hline Gastrosquise & 8 & Multifatorial \\
\hline Hidrocefalia Ligada ao X (OMIM 307000) & 1 & Monogênica \\
\hline Hipocondroplasia (OMIM 146000) & 1 & Monogênica \\
\hline Hipospádia & 1 & Multifatorial \\
\hline Malformação Adenomatosa Cística & 2 & Desconhecida \\
\hline Onfalocele & 1 & Heterogênea \\
\hline Pé-Torto Congênito & 5 & Multifatorial \\
\hline Polidactilia (OMIM 603596) & 2 & Monogênica \\
\hline Politelia (OMIM 163700) & 1 & Monogênica \\
\hline Sequência da Displasia Caudal & 1 & Desconhecida \\
\hline Sequência da Lateralidade & 1 & Desconhecida \\
\hline Sequência da Ruptura Amniótica & 4 & Desconhecida \\
\hline Sequência de Moebius & 1 & Desconhecida \\
\hline Síndrome Alcoólica Fetal & 2 & Ambiental \\
\hline Síndrome da Artogripose Distal & 1 & Monogênica \\
\hline Síndrome de Barber-Say (OMIM 209885) & 1 & Monogênica \\
\hline Síndrome de Dandy-Walker (OMIM 22020) & 1 & Monogênica \\
\hline Síndrome de DiGeorge (OMIM 188400) & 1 & Heterogênea \\
\hline Síndrome de Down & 9 & Cromossômica \\
\hline Síndrome de Edwards & 3 & Cromossômica \\
\hline Síndrome de Larsen (OMIN 150250) & 1 & Monogênica \\
\hline Síndrome de Patau & 1 & Cromossômica \\
\hline Síndrome de Pfeiffer* (OMIM 101600) & 1 & Monogênica \\
\hline Síndrome de Prune Belly (OMIM 100100) & 1 & Monogênica \\
\hline Síndrome de Townes Brocks (OMIM 107480) & 1 & Monogênica \\
\hline Síndrome Velocardiofacial* (OMIM 192430) & 2 & Heterogênea \\
\hline
\end{tabular}




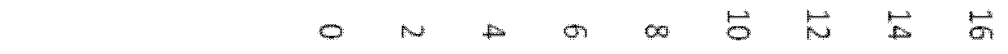

Defeitos Multiplos*

Candiopatia Congenita

Sindrome de Down

Gastrosquise

DFTN

pé-Torta congenito

Sequencia da Ruptura Amniótica

Disnupcto por Diabetes

Fenda Labial e/ou Palatina

Simdromede Edwards

Atresia de Esôfago

Malformacâo Adenomatosa Cistica

Polidactilia

Sindrome Alcoólica Felal

Sindrome Velocardiofacial

Anomalia Anometal

Anus Imper furado

Aplasia Congenta de cutis

Associacaso VATERF

Associaça VATERP*

Atelostrogenese Tipo III*

Atresia de Vias Biliares Extra-Hepaticas

Atresia intestinal

Campodactilla

colpocefalia

Complexo Membro Parede

Displasia Campomélica

Displasia Tanatoforica Tipo II

Distrofia Torácica de leune

Diverticulo de Meckel

Doenca au tossómica recessiva* Espectro Oculo-Auniculo-Vertebral

Hidrocefalia Ligada a $x$

Hipocondroplasia

Hipospådia

Onfalocele

Politelia

Sequenciada Displasia Caudal

Sequencia da Lateralidade

Sequência de Moebius

Sindrome da Artogripose Distal

sindrome de Barber-Say

Sindrome de oandy-Walker

Sindromede DiGeorge

Sindrome de Larsen

sindromede patai

Sindrome de Pfeiffer*

sindrome de Prune Delly

sindrome de Townes Procks

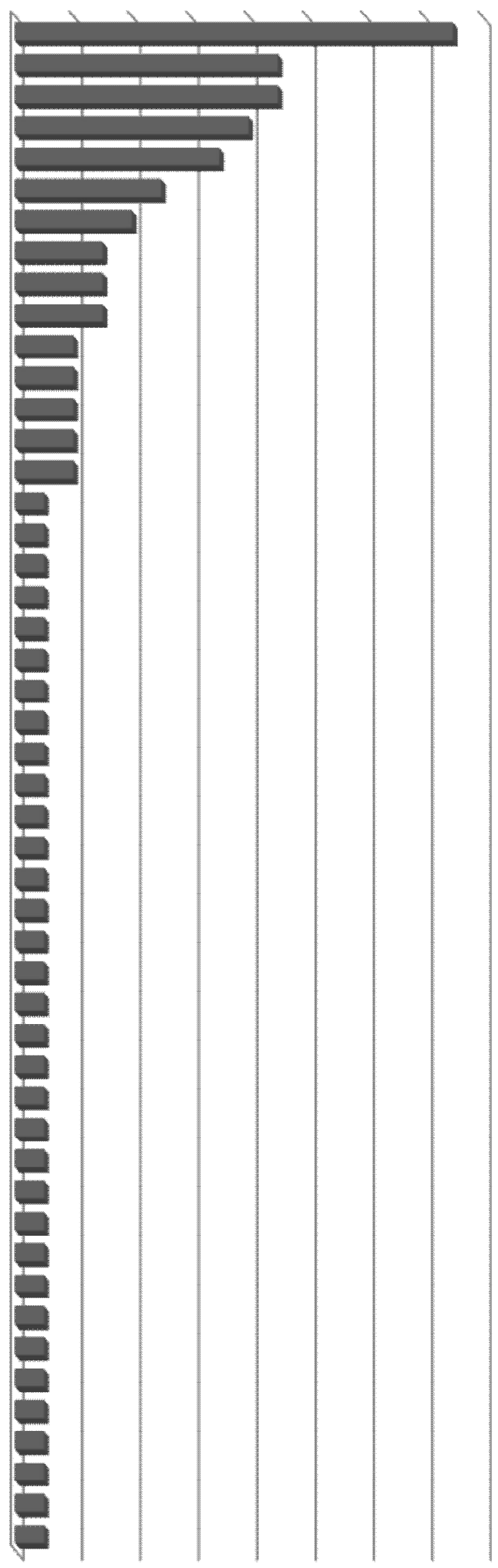




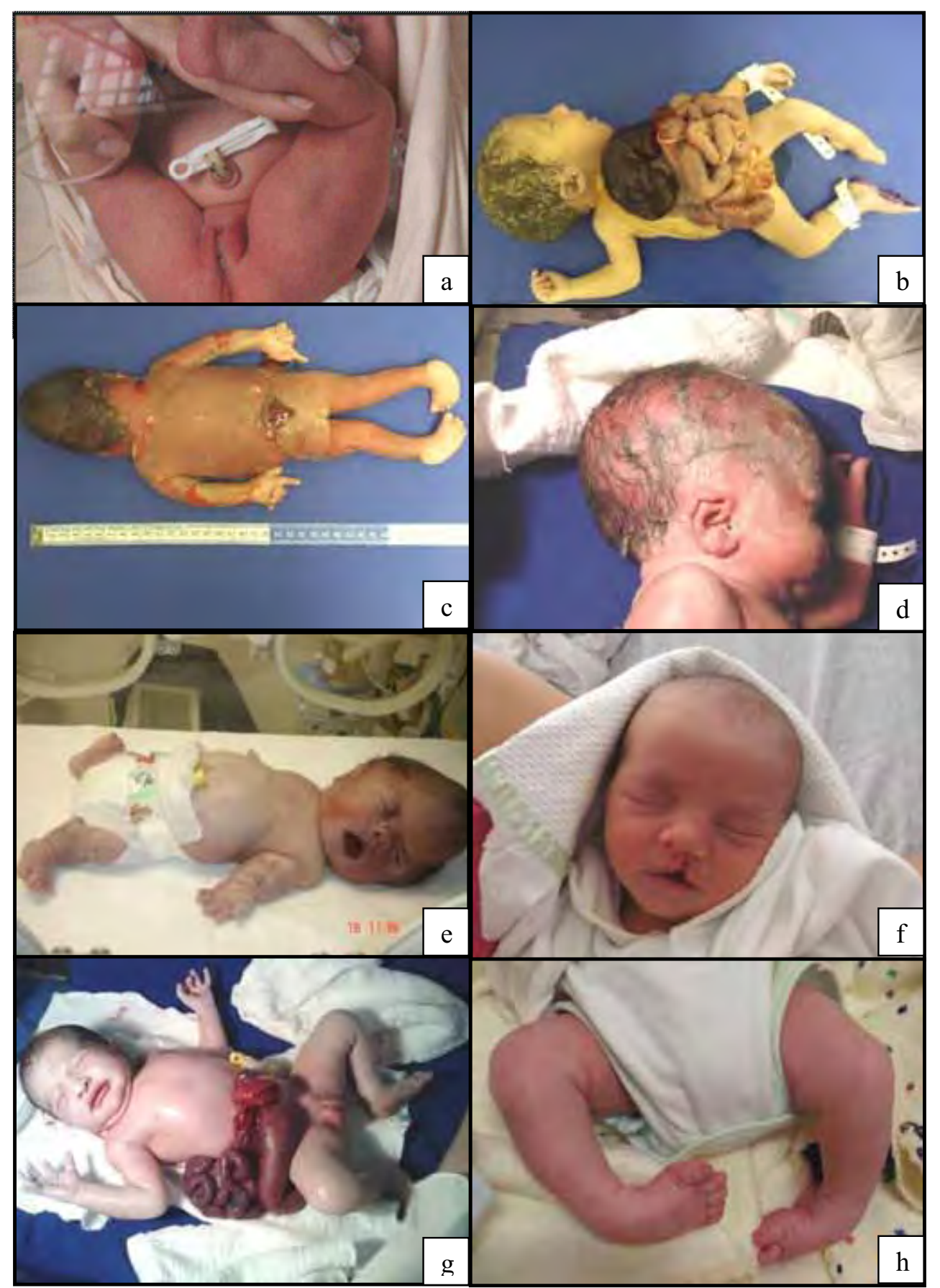

Figura 10. Pacientes com diagnóstico concluído. RN com anomalia anorretal (a); NT com complexo membro parede (b); NT com DFTN-mielomeningocele (c); RN com hidroanencefalia (d); RN com displasia tanatofórica tipo II (e); RN com fenda labial (f); RN com gastrosquise (g); RN com pé torto congênito (h). 


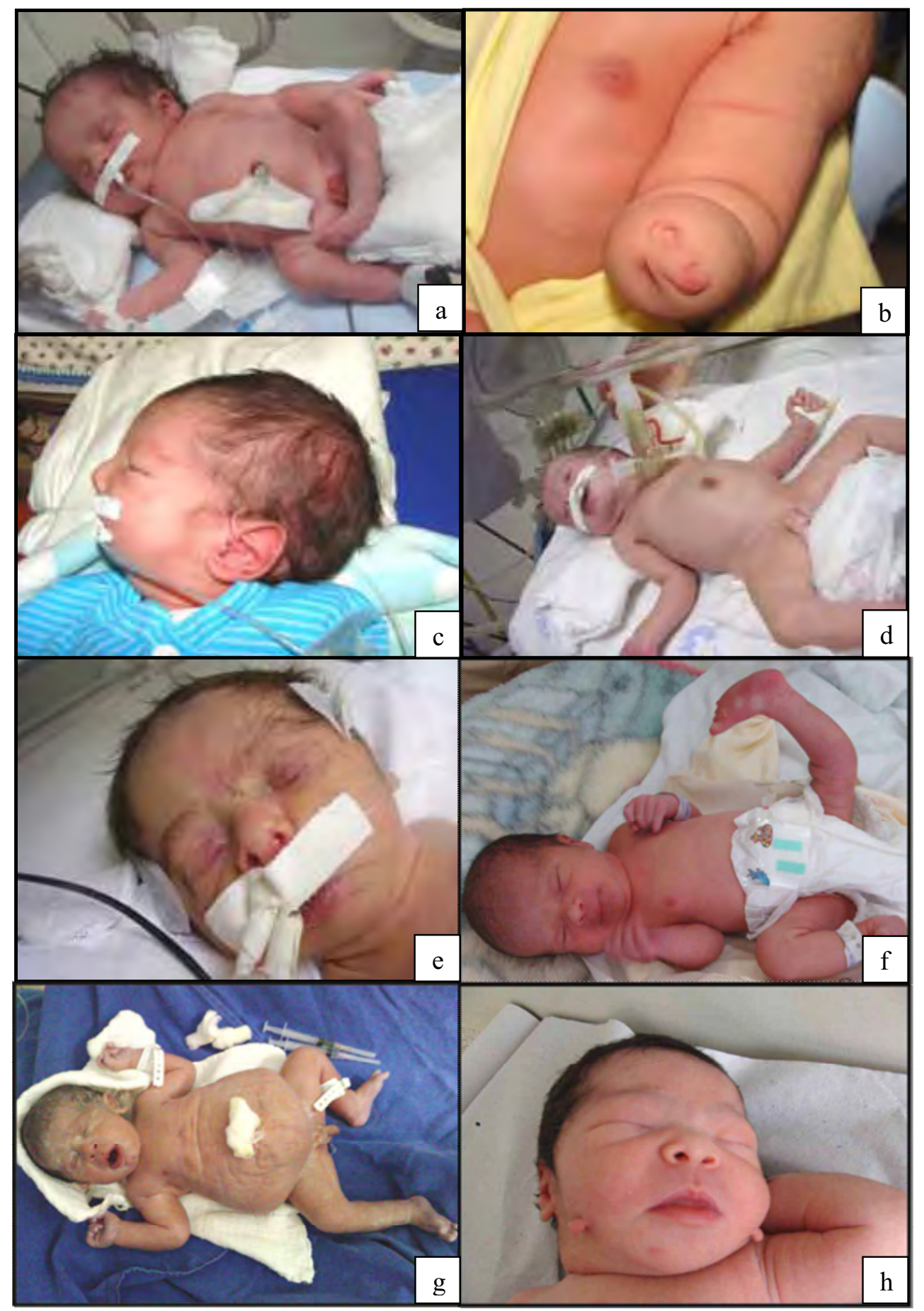

Figura 11. Pacientes com diagnóstico concluído. RN com sequência da displasia caudal (a); RN com sequência da ruptura anmiótica (b); RN com síndrome de Moebius (c); RN com síndrome da artogripose distal (d); RN com síndrome de Barbey-Say (e); RN com síndrome de Larsen (f); RN com síndrome de Prune-Belly (g); RN com síndrome de Townes Brocks (h). 


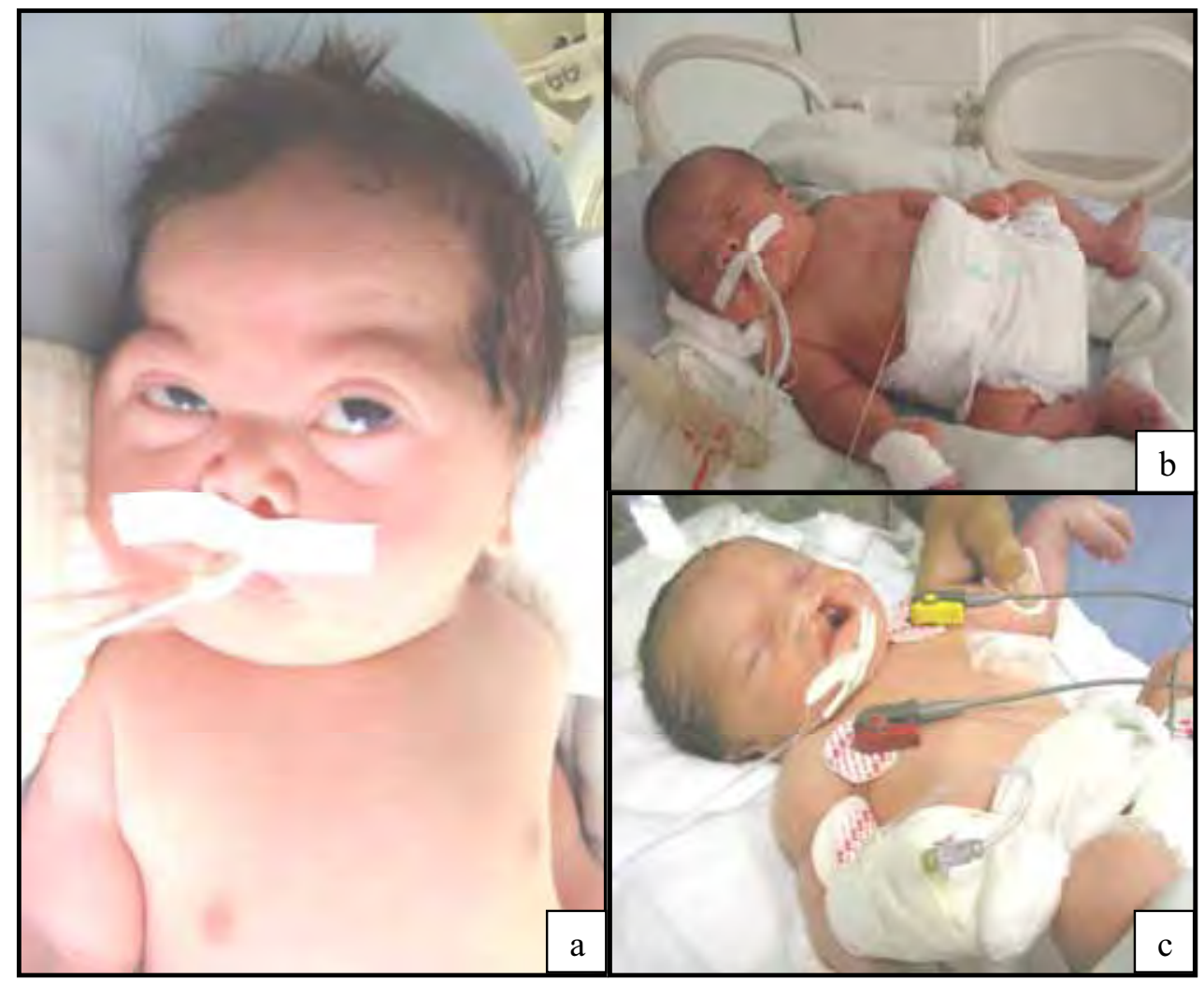

Figura 12. Pacientes com diagnóstico presumido. RN com suspeita de Atelosteogênese tipo III (a); RN com síndrome de Pfeiffer (b); RN com síndrome Velocardiofacial (c). 


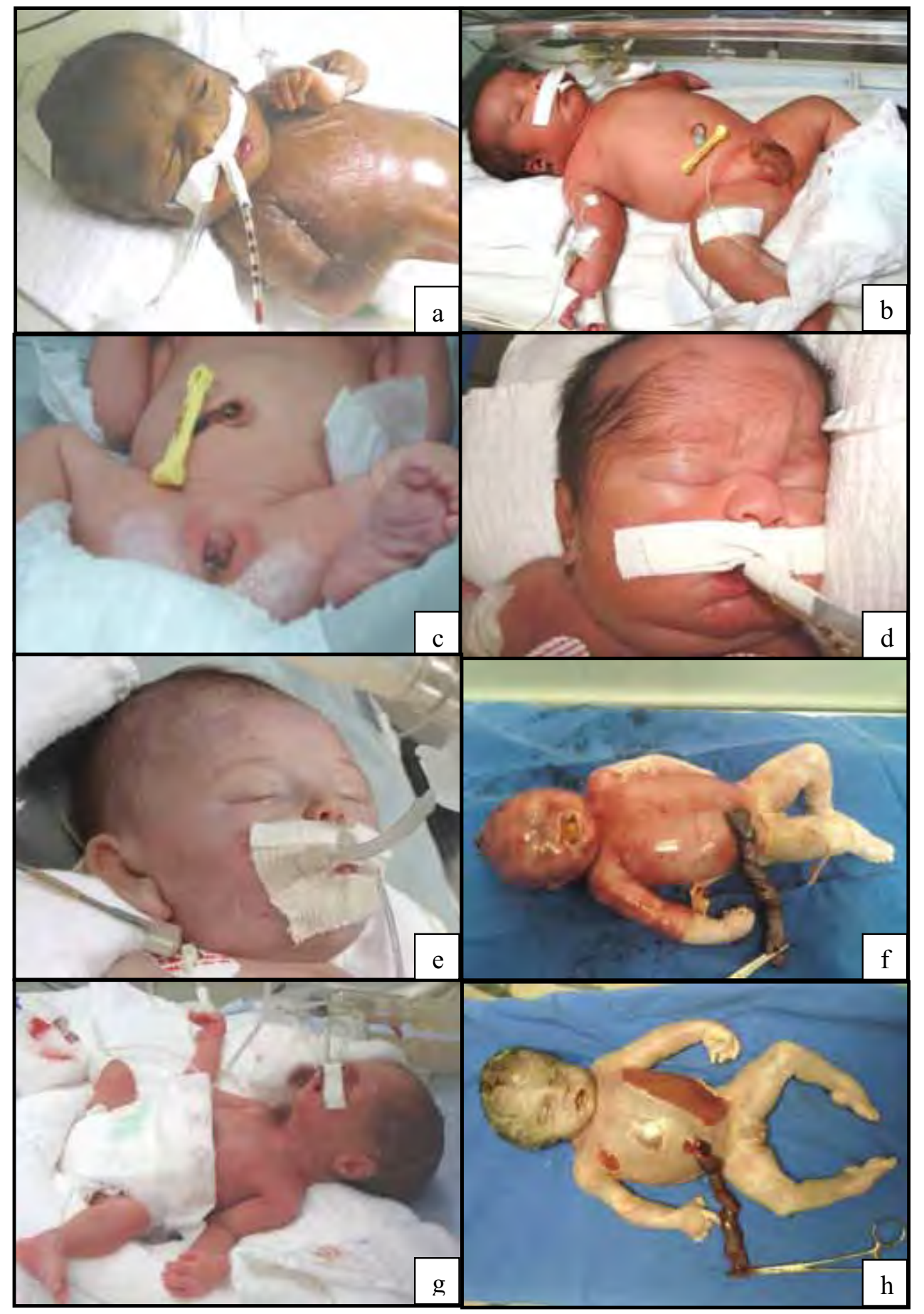

Figura 13a-h. Pacientes com defeitos múltiplos. 
Quanto à ocorrência, as cardiopatias congênitas isoladas foram os DC mais frequentes, observadas em nove casos (8\%) e as mais comuns foram: comunicação interatrial, comunicação interventricular, transposição das grandes artérias, ducto arterial pérvio e defeito do septo atrioventricular total.

A síndrome de Down foi diagnosticada em nove crianças (8\%), todas nascidas no HB, na proporção de um afetado para cada 336 nascimentos (considerando-se 3.026 partos no HB, no período). A média de idade das mães foi de 33 anos e variou de 16 a 46 anos e em cinco (55\%) a idade era superior a 35 anos, duas delas com mais de 40 anos.

A Gastrosquise isolada foi observada em oito (7\%) casos. A maioria das mães dos afetados com este DC (05 - 62,5\%) tinha idades até 20 anos.

Sete $(6,5 \%)$ pacientes foram diagnosticados como portadores de defeitos de fechamento de tubo neural (DFTN), um com hidroanencefalia e seis com mielomeningocele, dos quais quatro apresentaram também hidrocefalia e três Arnold Chiari tipo II.

O pé torto congênito isolado foi observado em cinco (4,5\%) casos. E a sequência da ruptura amniótica em quatro $(3,5 \%)$.

Como referido anteriormente, na categoria de defeitos múltiplos, ou seja, presença de dois ou mais defeitos maiores para os quais nenhum fator etiológico foi demonstrado ou suspeito, foram incluídos 15 casos (14\%). O Quadro 1 apresenta alguns dos DC observados.

A maioria dos pacientes apresentou DC de etiologia multifatorial, seguidos dos heterogênea, monogênica, desconhecida, cromossômica e ambiental (Tabela 4).

O preenchimento do Campo 34 da Declaração de Nascido Vivo foi um procedimento realizado em 97\% dos casos nascidos no HB. Entretanto, em 54 (69\%) o preenchimento ocorreu de forma correta e em 22 (28\%) de forma incorreta. Por exemplo, em dois casos com fácies típico de síndrome de Down, em um com Espectro Óculo-Aurículo-Vertebral e em outro com defeitos múltiplos, inclusive facies dismórfico, o campo foi assinalado como "não" para presença de malformação congênita e/ou anomalia cromossômica. Em nenhuma declaração a opção "ignorado" foi assinalada. 


\begin{tabular}{|c|c|c|}
\hline Sexo & Defeitos & Cariótipo \\
\hline \multirow[t]{2}{*}{ Feminino } & - Hérnia Diafragmática & $46, \mathrm{XX}$ \\
\hline & - Cardiopatia congênita & \\
\hline \multirow[t]{3}{*}{ Feminino } & - Cardiopatia congênita & Não realizado \\
\hline & - Insuficiência renal aguda & \\
\hline & - Fácies dismórfico & \\
\hline \multirow[t]{3}{*}{ Masculino } & - Cardiopatia congênita & $46, X Y$ \\
\hline & - Fenda labial & \\
\hline & - Polidactilia pós-axial bilateral em mãos & \\
\hline \multirow[t]{9}{*}{ Masculino } & - Occiptal proeminente & $46, X Y$ \\
\hline & - Orelha displásica e de implantação baixa & \\
\hline & - Hipertelorismo ocular & \\
\hline & - Pterigium colli & \\
\hline & - Micrognatia & \\
\hline & - Hipertricose & \\
\hline & - Prega simiesca na mão direita & \\
\hline & - Mamilos hiperplásicos & \\
\hline & - Hidronefrose grau III à direita & \\
\hline \multirow[t]{2}{*}{ Masculino } & - Hérnia diafragmática & $46, X Y$ \\
\hline & - Cardiopatia congênita & \\
\hline \multirow[t]{2}{*}{ Indefinido } & - Genitália ambígua & $46, X X$ \\
\hline & - Cardiopatia congênita & \\
\hline \multirow[t]{3}{*}{ Masculino } & - Fácies dismórfico & (Sem resultado) Ausência de crescimento \\
\hline & - Cardiopatia congênita & da cultura celular \\
\hline & - Insuficiência renal aguda & \\
\hline \multirow[t]{2}{*}{ Masculino } & - Microcefalia & Sem resultado \\
\hline & - Cardiopatia Congênita & \\
\hline \multirow[t]{2}{*}{ Feminino } & - Atresia de esôfago & \\
\hline & - Cardiopatia congênita & \\
\hline \multirow[t]{3}{*}{ Indefinido } & - Cardiopatia congênita & Não realizado \\
\hline & - Pé torto congênito bilateral & \\
\hline & - Hidropsia fetal & \\
\hline \multirow[t]{6}{*}{ Feminino } & - Artéria umbelical única & Não realizado \\
\hline & - Holoprosencefalia alobar & \\
\hline & - Microcefalia & \\
\hline & - Fenda labial bilateral & \\
\hline & - Punhos cerrados & \\
\hline & - Cardiopatia congênita & \\
\hline
\end{tabular}

Quadro 1- continua. Caracterização dos casos incluídos em defeitos múltiplos, quanto ao sexo, DC e cariótipo. 


\begin{tabular}{|c|c|c|}
\hline Sexo & Defeitos & Cariótipo \\
\hline \multirow[t]{11}{*}{ Feminino } & - Microcefalia & $46, \mathrm{XX}$ \\
\hline & - Fácies grosseiro & \\
\hline & - Orelhas displásicas e de implantação & \\
\hline & $\begin{array}{l}\text { baixa } \\
\text { - Anêndices nré-auriculares à esauerda }\end{array}$ & \\
\hline & - Hipertricose frontal & \\
\hline & - Nariz em bico & \\
\hline & - Maxilar hipoplásico & \\
\hline & - Palato estreito & \\
\hline & - Micrognatia & \\
\hline & - Hérnia inguinal à esquerda & \\
\hline & - Clinodactilia de $5^{\circ}$ quirodáctilo bilateral & \\
\hline \multirow[t]{8}{*}{ Feminino } & - Artéria umbilical única & Sem resultado \\
\hline & - Occipital proeminente & \\
\hline & Fontanela central ampla & \\
\hline & $\begin{array}{l}\text { - Orelhas de implantação baixa e } \\
\text { displásicas } \\
\text { - Micro e retrognatia }\end{array}$ & \\
\hline & - Narinas antivertidas & \\
\hline & - Cardiopatia congênita & \\
\hline & $\begin{array}{l}\text { - Abdômen globoso, distendido c/ diástase } \\
\text { de músculo reto abdominal } \\
\text { - Prega simesca bilateral }\end{array}$ & \\
\hline & - Hipertricose & \\
\hline \multirow[t]{4}{*}{ Feminino } & - Cisto de plexo coróide & Não realizado \\
\hline & - CIV membranosa & \\
\hline & $\begin{array}{l}\text { - Sobreposição de } 2^{\circ} \text { e } 5^{\circ} \text { quirodáctilos } \\
\text { sobre } 3^{\circ} \text { e } 4^{\circ} \\
\text {-Punhos cerrados }\end{array}$ & \\
\hline & - Pé torto congênito bilateral & \\
\hline \multirow[t]{5}{*}{ Masculino } & - Cardiopatia congênita & Não realizado \\
\hline & - Hipertelorismo ocular & \\
\hline & - Epicanto bilateral & \\
\hline & - Orelhas displásicas & \\
\hline & -Prega simiesca na mão esquerda & \\
\hline
\end{tabular}

Quadro 1- continuação.Caracterização dos casos incluídos em defeitos múltiplos, quanto ao sexo, DC e cariótipo. 
Tabela 4. Frequência dos DC por etiologia.

\begin{tabular}{lc}
\hline \multicolumn{1}{c}{ Etiologia } & Frequência \\
\hline Multifatorial & $29,0 \%$ \\
Heterogênea & $22,0 \%$ \\
Monogênica & $19,0 \%$ \\
Desconhecida & $13,5 \%$ \\
Cromossômica & $12,0 \%$ \\
Ambiental & $4,50 \%$ \\
\hline
\end{tabular}




\section{Discussão}

O conhecimento da prevalência dos DC em uma determinada população é fundamental não só por definir a existência ou não de uma situação em particular, mas também para comparar as características e possíveis fatores causais com os de outras populações reportadas na literatura mundial. O conhecimento destas características permite definir estratégias que podem ser tomadas para minimizar problemas específicos em determinados locais (MONTEIRO; COSTA, 2003).

A prevalência dos DC pode variar, uma vez que as descrições de dados populacionais correspondem a populações diferentes, com condições culturais, sociais, localização geográfica e origem genética diferentes. Além disso, os métodos de averiguação e os critérios de observação e classificação também diferem. A maior parte das descrições refere uma frequência entre 3 e 5\% de DC nas populações (PINTO; NASCIMENTO, 2007; RAMOS et al., 2009). Os poucos dados brasileiros disponíveis revelam frequências que variam entre 1,7 e 5\% (MOREIRA et al., 2001; CARVALHO et al., 2002; COSTA et al., 2006). A frequência de DC entre RN de uma maternidade do nordeste brasileiro obtida por Amorim et al. (2006) foi também $2,8 \%$.

Portanto, a prevalência de $2,8 \%$ obtida neste estudo está compatível com as previamente descritas. Mas, a prevalência pode estar subestimada, pelo fato de não haver registros oficiais do hospital onde este estudo foi realizado, do não preenchimento completo de alguns prontuários médicos e da possível não comunicação à equipe de pesquisadores deste trabalho de alguns casos de DC, principalmente com DC menores. Ainda existe a possibilidade de algumas malformações em órgãos internos, ou sem sintomas aparentes não terem sido diagnosticadas antes da alta hospitalar.

Realmente, quando se trata de DC, um fator importante na estimativa da incidência ou prevalência é que muitos, embora presentes ao nascimento, só serão diagnosticados em fases posteriores, pela manifestação tardia (HOROVITZ et al., 2005).

Embora a maioria dos $\mathrm{RN}$ fosse de etnia caucasóide ou oriental a frequência de DC encontrada não pode ser associada à etnia, inclusive pela alta miscigenação da população brasileira (AMORIM et al., 2006). A prevalência por sexo mostrou uma frequência um pouco maior de DC em homens (1,3:1), compatível com outros estudos, como o de Asindi e 
colaboradoes (1997), que observou a proporção de 1,2:1. Shaw et al. (2003) observaram uma prevalência $22 \%$ maior também em homens entre 2,5 milhões de $\mathrm{RN}$ da Califórnia, mas destaca a escassez de estudos sobre a diferença da prevalência de DC entre os sexos.

A maioria das mães observadas neste estudo eram primigestas e realizaram o seguimento médico pré-natal. Em 13\% delas foram notadas alterações no volume do líquido amniótico, oligo e polidrâmnia, que podem estar associadas a presença de anomalias fetais (CALONE, et al. 2009).

Aborto espontâneo anterior foi relatado por $15 \%$, a mesma frequência referida por Castro et al. (2006).

Da casuística, $63 \%$ das mães possuíam idades entre 20 e 34 anos, isto é, estavam dentro do intervalo que oferece menor risco para DC. Este resultado é esperado, pois este período também é o de maior taxa de fertilidade (VAN BALEN et al.,1997; RAMOS et al., 2009).

A idade materna é um dos fatores de risco para DC. Há uma relação entre idade materna mais precoce (até 20 anos) e a ocorrência de alguns DC, como a gastrosquise (RASMUSSEN; FRÍAS, 2008). Este dado pode ser confirmado pelos resultados aqui obtidos, que em $62,5 \%$ dos casos de gastrosquise isolada as mães tinham idades até 20 anos. Em idades mais avançadas o risco de cromossomopatias numéricas aumenta progressivamente (MORRIS; SAVVA, 2008; SANTOS et al., 2009) e este foi um fator de risco observado neste estudo, pois a maioria das mães de crianças com este tipo de anomalia tinha idade igual ou superior a 35 anos.

Não foi possível obter a idade de alguns pais, por serem desconhecidos ou pelo fato das mães desconhecerem a data de nascimento dos mesmos. Apenas o pai de uma criança com polidactilia tinha mais de 50 anos, idade considerada fator de risco para algumas afecções genéticas, inclusive algumas de etiologia multifatorial, mas não para este tipo de defeito (YANG et al., 2006; BAUJAT et al., 2008; MATERNA-KIRYLUK et al., 2009; COGSWELL et al., 2009).

O diabetes mellitus gestacional (DMG) foi presumido como um fator de risco em alguns casos. Tal condição está relacionada ao aparecimento de defeito de membros e do coração, entre outros. Neste estudo, todos os RN de mães que tiveram DMG possuíam algum tipo de cardiopatia, isolada ou associada. A prevalência de cardiopatias congênitas em $\mathrm{RN}$ de mães diabéticas é de 8,5\% entre nascidos vivos, motivo pelo qual o controle metabólico préconcepcional e nas primeiras semanas da gestação é muito importante (PACHECO et al., 2006; CORREA et al., 2008; HAERI et al., 2008). 
A consanguinidade parental foi observada em aproximadamente $2 \%$ dos casos. Foi maior do que a da população em geral da América do Sul, que é de $0,96 \%$, e semelhante à da população brasileira, que é de 1,6\% (LIASCOVICH et al., 2001). Contudo, foi menor do que as frequências previamente relatas de consanguinidade entre pais de crianças com DC no Brasil, que chega a 8,5\% (RAMOS et al., 2009). Isto pode ser explicado grande variação de consanguinidade entre casais por cidades e regiões do Brasil. Este estudo foi realizado em uma cidade de uma região desenvolvida do país, com taxas baixas de imigração de indivíduos de outras regiões menos desenvolvidas, onde a consanguidade é frequente.

Em dois casos aqui estudados a consanguinidade certamente foi o fator de risco. Uma das crianças tinha DC associados sem diagnóstico sindrômico e outra Distrofia Torácica de Jeune. Esta última, também conhecida como Distrofia Torácia Asfixiante, apresenta padrão de herança sabidamente autossômico recessivo e as anomalias mais comuns incluem o tórax pequeno e o encurtamento de membros. O óbito nestes casos é precoce, como ocorreu com o recém-nascido estudado, geralmente como consequência da asfixia com ou sem pneumonia (UÇAR et al., 2009).

Crianças prematuras têm maior chance de ter DC, que também são mais frequentes em crianças com peso inferior a $2.500 \mathrm{~g}$ e menores de $45 \mathrm{~cm}$ ao nascimento (DASTGIRI et al., 2003; KILSZTAJN et al., 2003; MONTEIRO; COSTA, 2003; PINTO; NASCIMENTO, 2007). A prematuridade, o baixo peso e estatura foram fatores importantes neste estudo, pela frequência alta que foram observados entre os RN com DC, compatível com os dados já descritos. A baixa estatura pode estar relacionada a problemas de crescimento intra-útero, a prematuridade, ao próprio defeito ou doença.

A morbidade relacionada aos DC é outro aspecto importante, inclusive pelo ônus gerado. A permanência no hospital de RN sem DC é breve, normalmente de 24 ou 48 horas, no caso de parto normal ou cesárea, respectivamente. O período médio de internação dos RN com DC estudados foi muito superior, de cerca de 33 dias. Dependendo da gravidade do defeito, o período de hospitalização pode ser extenso, como em um caso da casuística que foi de 254 dias.

Os DC respondem por uma taxa alta de mortalidade precoce e são mais frequentes entre natimortos (AMORIM et al., 2006). Nos países desenvolvidos os DC são responsáveis por $20 \%$ de óbitos neonatais (CASTRO et al., 2006). Em um estudo envolvendo mortes pediátricas num hospital infantil dos EUA, 34,4\% das mesmas ocorreram em virtude de DC (STEVENSON; CAREY, 2004). No Brasil os dados oficiais são escassos, mas os DC respondem por quase $30 \%$ dos óbitos em menores de um ano em alguns estados, como no Rio 
Grande do Sul. A evolução para óbito pode ocorrer por diferentes causas relacionadas aos defeitos de nascimento, pela prematuridade ou por causas ambientais, considerando-se entre estas últimas as complicações de intervenções clínicas ou cirúrgicas e as infecções (GUERRA et al., 2008). Neste estudo 6\% dos casos com DC eram natimortos e o óbito pré-natal pode ser explicado pela presença de DC múltiplos e graves, observados em todos eles. Além disso, a maioria dos casos de óbito de $\mathrm{RN}$ ocorreu no período neonatal. Portanto a frequência de óbito obtida aqui pode ser considerada alta e este como uma das consequências dos DC.

Até dois terços dos casos com DC nascem de parto cesárea (TAN et al., 2005). O número elevado, como observado na casuística avaliada, pode ser consequência de indicação a partir do diagnóstico pré-natal do DC, como os de gastrosquise, de casos com risco de ruptura das membranas que recobrem as mielomeningoceles e onfaloceles e de hidrocefalia grave (WEN et al., 2000; DASTGIRI et al., 2003). Porém, a opção por cesareana também é muito comum no Brasil, independente da saúde do feto (FAÚNDES; CECATTI, 1991; FREITAS et al., 2005).

Neste estudo ocorreram seis casos de gemelaridade. Sabe-se que a frequência de DC é maior em gêmeos, quando comparados com não gêmeos, principalmente nas gestações monozigóticas (LEITE et al., 2001). Em dois casos a gemelaridade pode ter sido um fator de risco, pois as gestações eram monozigóticas.

Quanto a recorrência em algum parente, esta foi observada em 7\% dos casos, que pode ser relacionada a fator de risco genético, ou seja, à predisposição familial (CASTRO et al., 2006). A ocorrência em um dos genitores foi observada em três casos (3\%), um deles de fissura lábio-palatal na mãe, um de Hipocondroplasia também na mãe e um de polidactilia no pai.

As fissuras congênitas de lábio e palato são as malformações orofaciais mais frequentes. Acometem cerca de $0,15 \%$ dos nascidos vivos e $5 \%$ dos filhos quando um genitor é afetado (SOUZA-FREITAS et al., 2004). Ocorrem entre o período embrionário e início do fetal. A fenda labial e a fenda palatina têm origem antes de 36 dias e 10 semanas de gestação, respectivamente. Resultam da deficiência da fusão dos processos maxilares e médio nasal, impedindo o crescimento completo dessas estruturas e em $42 \%$ dos casos descritos pela literatura aparecem associadas (JONES, 2007). A etiologia é complexa e envolve fatores genéticos e ambientais, podendo se originar da influência de diversos agente teratogênicos e de falhas de estruturas ósseas e tecidual, que comprometem o desenvolvimento embrionário. Dentre as causas descritas estão: hereditariedade, doenças durante a gravidez (sífilis e 
rubéola), alimentação inadequada da futura mãe, entre outras (CUNHA et al., 2004). A etiologia multifatorial é proposta na maioria dos casos (GRAZIOSI et al., 2000).

A Hipocondroplasia é uma condição herdada de forma autossômica dominante. Tem uma incidência de aproximadamente um doze avos da Acondroplasia e se diferencia desta condição pela relativa ausência de envolvimento craniofacial e pelas características mais leves nas mãos e na coluna. As alterações incluem os membros curtos, estreitamento caudal da coluna e baixo peso e estatura ao nascimento. O RN aqui estudado apresentou peso e estatura ao nascimento, respectivamente de $2.415 \mathrm{~g}$ e $42 \mathrm{~cm}$. A estatura da mãe era de $146 \mathrm{~cm}$ e ela apresentava arqueamento para fora dos membros inferiores e o genu varo que também são observados nos afetados e se tornam mais evidentes com a idade e o aumento do peso (JONES, 2007; OMIN, 2009). O diagnóstico do RN foi sugerido a partir da avaliação da mãe.

A Politelia foi a anomalia recorrente no terceiro caso, com pai afetado. A prevalência varia de 0,22 a $5 \%$ e ocorre em homens e mulheres na mesma proporção. Em RN a presença de mamilos extras aparece como um defeito tênue, em forma de máculas de um a três milímetros (EICHENFIELD et al., 2009). Alguns autores sugeriram que este defeito pode estar associado com outros, principalmente com malformações do trato urinário (MERCADO et al., 1998).

Em três casos estudados a ocorrência do mesmo defeito foi observada na irmandade, dois de cardiopatia, que isoladas têm etiologia multifatorial e risco de recorrência de cerca de 3\% (MIYAGUE et al., 2003), e um de defeito de fechamento de tubo neural, que segue o mesmo tipo de herança (SANTOS; PEREIRA, 2007).

Quanto à presença de anomalias cromossômicas, 100\% eram numéricas, trissomias de autossomos, o que é explicado pelo fato das aneuploidias serem o tipo de distúrbio cromossômico mais frequente na espécie humana (GALERA et al., 2009; RAMOS et al., 2009).

Somente em $40 \%$ o diagnóstico de uma síndrome conhecida é possível (JONES, 2007). Neste estudo, o diagnóstico conclusivo foi possível em 89 casos (81\%), o que facilitou o processo de Aconselhamento Genético da famílias. Este percentual foi atingido provavelmente em função de terem sido também considerados os DC isolados, dos recursos hospitalares disponíveis, pois o $\mathrm{HB}$ é um hospital escola de referência e da atuação multidisciplinar na investigação diagnóstica. Na ausência do diagnóstico, além do prejuízo quanto a estratégias de tratamento e prevenção, há um prejuízo no Aconselhamento Genético, pois não é possível precisar os riscos de recorrência (BRUNONI, 2002). 
As anomalias cardíacas isoladas, síndrome de Down, seguidas por gastrosquise, defeitos de fechamento de tubo neural, pé-torto congênito e sequência da ruptura amniótica foram os DC mais frequentes.

As anomalias isoladas dos sistemas cardiovascular e principalmente do urinário não são facilmente detectáveis ao nascimento e seu diagnóstico implica em atenção pós-natal adequada (GUERRA et al., 2008). As urinárias podem acometer cerca de 10\% dos RN com DC e em alguns estudos são referidas como as mais frequentemente encontradas (CALONE et al., 2009). Neste estudo as anomalias do sistema urinário foram observadas apenas em pacientes com DC múltiplos, talvez pelo fato de que na maioria das vezes são assintomáticas no período neonatal.

As anomalias congênitas do coração e dos grandes vasos isoladas são responsáveis por alta mortalidade no primeiro ano de vida (MAJNEMER et al., 2009). A incidência descrita varia de 2 a 10 por 1.000 nascidos vivos e a etiologia é multifatorial, com risco de recorrência de cerca de 3\% (MIYAGUE et al., 2003; SILVA; GOMES, 2002). Neste estudo, os defeitos cardíacos isolados foram os mais frequentes, com incidência estimada de 3:1.000 RN.

A incidência para síndrome de Down é de cerca um para cada 660 recém-nascidos e é o padrão de malformação mais comum na população (GIRISHA et al., 2007; ALIO et al., 2008). A idade materna foi um fator de risco importante neste estudo, uma vez que em cinco (55\%) dos nove casos detectados a mãe tinha mais de 35 anos de idade. Entre os nascidos no Hospital, a proporção obtida foi de aproximadamente 1:330 nascidos vivos, ou seja, maior do que as descritas. Este achado pode ser justificado em parte pelo fato de que duas mães já tinham indicação para procurar o Hospital por alterações detectadas na triagem ultrassonográfica (translucência nucal aumentada) e/ou idade avançada.

A gastrosquise é uma anomalia caracterizada por defeito de fechamento da parede abdominal anterior fetal, paraumbilical, com evisceração dos órgãos abdominais, que ocorre no primeiro trimestre da gravidez. A ocorrência é esporádica e com herança multifatorial na maioria dos casos isolados, como nos aqui relatados. Também pode ocorrer associada a outras anomalias em síndromes genéticas. Afeta cerca de 1:4.000 nascidos vivos (LAMMER et al., 2008) e neste estudo ocorreu em 2,64:1.000 RN. Esse valor elevado pode ser explicado pelo fato dessa anomalia ser detectada na ultra-sonografia a partir da $13^{\mathrm{a}}-14^{\mathrm{a}}$ semanas do período gestacional (LUND et al., 2007) e do HB ser um centro de referência, preparado para o tratamento cirúrgico deste tipo de defeito. Dos afetados, $75 \%$ sobreviveram após o tratamento cirúrgico adequado e cuidados em unidade neonatal de tratamento intensivo, taxa semelhante à descrita na literatura, que é de cerca de 90\% (TOWER et al., 2008). 
Os defeitos de fechamento do tubo neural (DFTN) são anomalias congênitas resultantes do incorreto ou incompleto fechamento do tubo neural embrionário, que ocorre até a quarta semana de embriogênese. Embora a incidência varie consideravelmente nas diversas regiões geográficas, afetam 1:1.000 nascidos vivos. Estudos brasileiros descrevem 0,83:1.000 e 1,87:1.000 nascidos vivos (SANTOS; PEREIRA, 2007; PACHECO et al., 2009). Neste estudo foram observados sete casos (apenas um era natimorto), ou seja, 1,98:1.000 nascidos vivos.

Embora a etiologia dos DFTN ainda não esteja bem esclarecida, é considerada a herança multifatorial na maioria dos casos. Entre os fatores de risco maternos estão o diabetes mellitus, obesidade, hipertermia e deficiência de ácido fólico. Os genes envolvidos mais estudados são os associados ao metabolismo do ácido fólico, particularmente o gene da enzima 5,10 metileno-tetra-hidrofolato-redutase. O mecanismo exato de como o ácido fólico está envolvido na embriogênese do tubo neural é ainda pouco compreendido e a suplementação periconcepcional e durante o primeiro trimestre de gravidez reduz em 50 a $70 \%$ os riscos de ocorrência ou recorrência (RAY et al., 2005; BOYLES et al., 2006; PACHECO et al., 2009).

Em um caso de DFTN observado neste estudo a mãe era obesa e diabética e nenhuma delas tomou ácido fólico no período periconcepcional, nem mesmo a mãe que teve um filho anterior afetado, apesar de ter sido esclarecida sobre a importância deste procedimento. Estes provavelmente foram os fatores de risco envolvidos nos casos estudados.

Quarenta países instituíram a fortificação de alimentos consumidos em larga escala com ácido fólico como uma estratégia de suplementação à população de gestantes (SANTOS, PEREIRA, 2007). No Brasil, a partir de junho de 2004, a fortificação das farinhas de trigo e milho com ácido fólico passou a ser obrigatória (HOROVITZ et al., 2005), mas estes alimentos nem sempre estão entre os rotineiramente consumidos pela população de baixo poder aquisitivo.

Pé torto congênito é um termo genérico utilizado para descrever uma afecção congênita complexa do pé, caracterizada por equinismo, cavismo, varismo e adução acentuados, presente isoladamente ou em associação entre 2,17:1.000 e 6,84:1.000 RN (PEREIRA et al., 2008; PINTO et al., 2008). Neste estudo, a forma isolada foi observada em 1,65:1.000 e, quando considerados todos os casos, em 4,6:1.000 $\mathrm{RN}$, valor dentro do esperado.

A sequência da ruptura amniótica também foi um dos defeitos mais frequentes. Ocorre como consequência da ruptura amniótica, pequenas faixas de âminio envolvem as estruturas 
em desenvolvimento (geralmente os membros), provocando constrições anulares, pseudosindactilia, amputações intra-uterinas e constrições no cordão umbilical (JONES, 2007). Um estudo na América Latina encontrou uma taxa de prevalência de aproximadamente 1:11.000 nascimentos (ORIOLI et al., 2003).

$\mathrm{Na}$ literatura não são encontrados muitos trabalhos que avaliaram de modo similar os RN com DC associados, que são categorizados de maneiras diferentes. Em apenas 40\% dos casos o diagnóstico etiológico é possível, associado a síndromes, sequências, complexos ou a eventos disruptivos (JONES, 2007). Na Arábia Saudita, Asindi et al. (1997) encontraram uma frequência de 8,8\% de crianças com associações de múltiplas anomalias. Na cidade de Caxias do Sul, na região sul do Brasil, Calone et al. (2009) observaram associação de malformações em $0,4 \%$ dos 14.351 recém-nascidos estudados, mas foram excluídos os $\mathrm{RN}$ com síndrome de Down, aqueles cujos dados estavam incompletos e os casos de gemelaridade. Dois ou mais DC associados foram denominados por CASTRO et al. (2006) de malformações múltiplas e foram observados em $8,1 \%$ dos $\mathrm{RN}$ da cidade de Pelotas, também do sul do Brasil. $\mathrm{Na}$ casuística estudada os DC associados foram observados em $43(1,4 \%)$ dos $3.026 \mathrm{RN}$ e em $53 \%$ dos casos de DC. Destes últimos, 15 (14\%) eram defeitos múltiplos, ou seja, uma combinação de dois ou mais defeitos maiores para os quais nenhum fator etiológico foi demonstrado ou suspeito.

Quanto aos tipos de DC com etiologia genética envolvida, os de padrão multifatorial foram os mais frequentes, seguidos dos monogênicos e cromossômicos, conforme esperado (NUSSBAUM et al., 2007).

Quanto ao preenchimento do Campo 34 da Declaração de Nascido Vivo do Brasil, de acordo com Guerra et al. (2008), o percentual de não preenchimento ou do preenchimento da opção "ignorado" ainda é alto na maioria das maternidades, atingindo até $21 \%$. Este problema não ocorreu com os casos registrados no HB, pois a opção "ignorado" não foi assinalada em nenhum dos casos de DC e somente em dois o campo permaneceu em branco. Entretanto, em $28 \%$ dos casos o preenchimento foi incorreto, pois o RN possuía um ou mais defeitos congênitos e a opção assinalada foi "não". O Sistema de Informação sobre Nascidos Vivos (SINASC) é hoje uma fonte de informações para estudos de prevalência de DC e o problema observado nesta casuística, em um Hospital escola da região mais desenvolvida do Brasil, provavelmente se repete em outros hospitais, o que compromete os dados oficiais. Portanto, há necessidade de desenvolver estratégias para aprimorar o registro de DC no Campo 34 da Declaração de Nascidos Vivos (GEREMIAS et al., 2009). 
Este estudo é o primeiro que avalia DC no município de São José do Rio Preto. Os procedimentos de avaliação clínica, fotos para estudo e exame do cariótipo eram procedimentos feitos rotineiramente no $\mathrm{HB}$ nos casos de DC maiores, para investigação diagnóstica e Aconselhamento Genético, mas apenas nos casos solicitados por solicitação de pareceres das equipes médicas. A sistemática de abordagem utilizada neste estudo possibilitou a ampliação do número de casos avaliados e permitiu uma integração maior entre os profissionais de diferentes áreas de especialização. Portanto, além da contribuição para a melhora da sistemática de trabalho no hospital, os dados obtidos forneceram subsídios para as equipes médicas e facilitaram o processo de Aconselhamento Genético das famílias. Poderão também ser úteis na elaboração de estratégias de prevenção de DC. 


\section{Conclusões}

1. A prevalência de defeitos congênitos entre os recém-nascidos e natimortos do Hospital de Base de São José do Rio Preto/ SP é semelhante aos dados da literatura.

2. Os defeitos congênitos de herança multifatorial são os mais frequentes, seguidos pelos defeitos de etiologia heterogênea, monogênica, desconhecida, cromossômica e ambiental.

3. A maior parte dos defeitos congênitos sem causa conhecida são múltiplos.

4. A incidência dos defeitos menores pode estar subestimada na população estudada.

5. A idade materna precoce e avançada, a consanguinidade parental e a presença de defeitos congênitos na família são fatores de risco para defeitos congênitos.

6. A hospitalização prolongada e o óbito são algumas consequências dos defeitos de nascimento.

7. O diagnóstico dos defeitos congênitos é possível na maioria dos casos em que a abordagem dos recém-nascidos é feita por profissionais de diferentes especialidades.

8. Os profissionais da saúde envolvidos com o preenchimento do Campo 34 da Declaração de Nascidos Vivos do Brasil devem ser esclarecidos sobre a importância do preenchimento adequado do mesmo.

9. A conclusão do diagnóstico nos casos de defeitos congênitos permite a realização do Aconselhamento Genético de forma mais adequada para as famílias. 


\section{REFERÊNCIAS}

ALIO, J. J.; LORENZO, J.; IGLESIAS, C. Cranial base growth in patients with Down syndrome: a longitudinal study. American Journal of Orthodontics and Dentofacial Orthopedics, Saint Louis, v. 133, n. 5, p. 729-737, May 2008.

AL-JARALLAH, A. S. Down's syndrome and the pattern of congenital heart disease in a community with high parental consanguinity. Medical Science Monitor: international medical journal of experimental and clinical research, Poland, v. 15, n. 8, p. 409-412, Aug. 2009.

AMORIM, M. M. R.; VILELA, P. C.; SANTOS, A. R. V. D.; LIMA, A. L. M. V. MELO , E. F. P.; BERNARDES, H. F.; FILHO, P. F. B. M.; GUIMARÃES, V. B. Impact of congenital malformations on perinatal and neonatal mortality in an university maternity hospital in Recife. Revista Brasileira de Saúde Materna e Infantil, Recife, v. 6, n.1, p. 19-25, maio, 2006.

ANZIVINO, E.; FIORITI, D.; MISCHITELLI, M.; BELLIZZI, A.; BARUCCA, V.; CHIARINI, F.; PIETROPAOLO, V. Herpes simplex virus infection in pregnancy and in neonate: status of art of epidemiology, diagnosis, therapy and prevention. Virology Journal, England, v. 6, n. 40, Apr. 2009.

ASINDI, A. A.; AL HIFZI, I.; BASSUNI, A. W. Major congenital malformations among Saudi infants admitted to Asir Central Hospital. Annals of Saudi Medicine, n. 2, p. 250-253, 1997.

BAUJAT, G.; LEGEAI-MALLET, L.; FINIDORI, G.; CORMIER-DAIRE, V.; LE MERRER, M. Achondroplasia. Best Practice \& Research Rheumatology, v. 22, n. 1 p. 3 18, Mar. 2008.

BONANNI, P.; BECHINI, A.; BOCCALINI, S.; PERUZZI, M.; TISCIONE, E.; BONCOMPAGNI, G.; MANNELLI, F.; SALMASO, S.; FILIA, A.; TAI, M. C. D. Progress in Italy in control and elimination of measles and congenital rubella. Vaccine, Kidlinton, v. 25, n. 16, p. 3105-3110, Apr. 2007.

BOYLES, A. B.; BILLUPS, A. V.; DEAK, K. L.; SIEGEL, D. G.; MEHLTRETTER, L.; SLIFER, S. H.; BASSUK, A. G.; KESSLER, J. A.; REED, M. C.; NIJHOUT, H. F.; GEORGE, T. M.; ENTERLINE, D. S.; GILBERT, J. R.; SPEER, M. C. Neural Tube defects and folate pathway genes: family-based association tests of gene-gene and gene-environment interactions. Environmental Health Perspectives, v. 114, n. 10, p. 1547-1552, Oct. 2006. 
BRONBERG, R.; ALFARO, E.; CHAVES, E.; DIPIERRI, J. Analysis of infant mortality from congenital malformations in Argentina during the 2002-2006 period. Archivos Argentinos de Pediatría, v. 107, n. 3, p. 203-211, jun. 2009.

BRUNONI, D. Aconselhamento Genético. Ciência e Saúde Coletiva, Rio de Janeiro, v. 7, n. 1, p. 101-107, 2002.

CABRAL-OLIVEIRA, F. C.; ALBUQUERQUE, L. C.; PAULO, C. S.; LACERDA, A. M.; FORTUNA, F. N.; FARIAS, S. PORTELA, D.; CHRISTI, A.; ACOSTA, A. X. Defeitos Congênitos - Tópicos Relevantes. Gazeta Médica da Bahia, Salvador, v. 77, n. 1, p. 32-39, 2007.

CALONE, A.; MADI, J. M.; ARAÚJO, B. F.; ZATTI, H.; MADI, S. R. C.; LORENCETTI, J.; MARCON, N. O. Malformações congênitas: aspectos maternos e periatais. Revista AMRIGS, Porto Alegre, v. 53, n. 3, p. 226-230, jul./set. 2009.

CARMICHAEL, S. L.; YANG, W.; HERRING, A.; ABRAMS, B.; SHAW, G. M. Maternal food insecurity is associated with increased risk of certain birth defects. The Journal of Nutrition, v. 137, n. 9, p. 2087-2092, Sep. 2007.

CARVALHO, M. H. B.; BRIZOT, M. L.; LOPES, L. M.; CHIBA, C. H.; MIYADAHIRA, S.; ZUGAIB, M. Delection of fetal structural abnormalities at the 11-14 week ultrasound scan. Prenatal Diagnosis, v. 22, n. 1, p. 1-4, 2002.

CASE, A. P.; CANFIELD, M. A. Methods for developing useful estimates of the costs associated with birth defects. Birth Defects Research. Part A, Clinical and molecular teratology, v. 85, n. 11, p. 920-924, Nov. 2009.

CASTRO, M. L. S.; CUNHA, C. J.; MOREIRA, P. B.; FERNÁNDEZ, R. R.; GARCIAS, G. L.; MARTINO-RÖTH, M. G. Frequência das malformações múltiplas em recém-nascidos na cidade de pelotas, Rio Grande do Sul, Brasil, e fatores sócio-demográficos associados.

Cadernos de Saúde Pública, Rio de Janeiro, v. 22, n. 5, p. 1009-1015, maio, 2006.

CHRISTIANSON, A; MODELL, B. Medical genetics in developing countries. Annual Review of Genomics and Human Genetics, v. 5, n. 65, p. 219- 265, Sep. 2004. 
COGSWELL, M. E.; BITSKO, R. H.; ANDERKA, M.; CATON, A. R.; FELDKAMP, M. L.; HOCKETT SHERLOCK, S. M.; MEYER, R. E.; RAMADHANI, T.; ROBBINS, J. M.; SHAW, G. M.; MATHEWS, T. J.; ROYLE, M.; REEFHUIS, J.; National Birth Defects Prevention Study. Control Selection and Participation in an Ongoing, Population-based, CaseControl Study of Birth Defects. American Journal of Epidemiology, v. 170, n. 8, p. 975 985, Oct. 2009.

COLVIN, L.; BOWER, C. A retrospective population-based study of childhood hospital admissions with record linkage to a birth defects registry. BMC Pediatrics, v. 9, n. 32, May 2009.

CORREA, A.; GILBOA, S. M.; BESSER, L. M.; BOTTO, L. D.; MOORE, C. A.; HOBBS, C. A.; ClEVES, M. A.; RIEHLE-COLARUSSO, T. J.; WALLER, D. K.; REECE, E. A. Diabetes mellitus and birth defects, American Journal of Obstetrics and Gynecology, v. 199, n. 3, p. 237e1-9, 2008.

COSTA, C. M. S.; GAMA, S. G. N.; LEAL, M. C. Congenital malformations in Rio de Janeiro, Brazil: prevalence and associated factors. Cadernos de Saúde Pública, Rio de Janeiro, v. 22, n. 11, p. 2423-2431, 2006.

CUNHA, E. C. M.; FONTANA, R.; FONTANA, T.; SILVA, W. R.; MOREIRA, Q. V. P.; GARCIAS, G. L.; ROTH, M. G. M. Antropometria e fatores de risco em recém-nascidos com fendas faciais. Revista Brasileira de Epidemiologia, São Paulo,v. 7, n. 4, dez. 2004.

DASTGIRI, S.; GILMOUR, W. H.; STONE, D. H. Survival of children born with congenital anomalies. Archives of Disease in Childhood, v. 88, n. 5, p. 391-394, 2003.

DE SANTIS, M.; CESARI, E.; LIGATO, M. S.; NOBILI, E.; STRAFACE, G.;

CAVALIERE, A.; CARUSO, A. Prenatal drug exposure and teratological risk: one-year experience of an Italian Teratology Information Service. Medical Science Monitor: international medical journal of experimental and clinical research, v. 14, n. 2, p.1-8, Feb. 2008.

DE VIGAN, C.; KHOSHNOOD, B.; LHOMME, V. V.; GOUJARD, J.; GOFFINET, F. Prévalence et diagnostic prénatal des malformations em population parisienne:vingt ans de surveillance par lê Registre des malformations congénitales de Paris. Journal De Gynecologie Obstetrique Et Biologie De La Reproduction, Paris, v, 34, n.1, p.8-16. 2005.

DI CARLO, P.; ROMANO, A.; SCHIMMENTI, M. G.; MAZZOLA, A.; TITONE, L. Materno-fetal Toxoplasma gondii infection: critical review of available diagnostic methods. Le Infezioni in Medicina: rivista periodica di eziologia, epidemiologia, diagnostica, clinica e terapia delle patologie infettive, v. 16, n. 1, p. 28-32, Mar. 2008. 
DODE, M. A.; SANTOS, S. I. Fatores de risco para diabetes gestacional na coorte de nascimentos em Pelotas, Rio Grande do Sul, Brasil, 2004. Cadernos de Saúde Pública, Rio de Janeiro, v. 25, n. 5, p. 1141-1152, maio 2009.

EICHENFIELD L. F.; FRIEDEN, I. J.; ESTERLY, N. B. Dermatología neonatal. 2. ed. Barcelona: Elsevier, 2009.

FACULDADE DE MEDICINA DE SÃO JOSÉ DO RIO PRETO. O Hospital de Base. Disponível em: < http://www.famerp.br/faculdade/hb.html >. Acesso em: 19 out. 2009.

FAÚNDES, A.; CECATTI, J. G. A operação Cesárea no Brasil. Incidência, tendências, causas, consequências e propostas de ação. Cadernos de Saúde Pública, Rio de Janeiro,v.7,n. 2, Apr./June 1991.

FREITAS, P. F.; DRACHLER, M .L.; LEITE, J. C. C.; GRASSI, P. R. Social inequalities in cesarean section rates in primiparae, Southern Brazil. Revista de Saúde Pública, São Paulo, v. 39, n. 5 , Oct. 2005.

GALERA, B. B.; GODOY, G. C. S.; FERNANDES, A. M.; SILVESTRE, F. G.; DUARTE, E. C.; GALERA, M. F. Estudo descritivo da demanda de um Serviço de Citogenética Clínica no Estado do Mato Grosso: 2003 a 2007. Revista de Pediatria, São Paulo, v. 31, n. 1, p. 3440, 2009.

GANDHOKE, I.; AGGARWAL, R.; HUSSAIN, S. A.; PASHA, S. T.; SETHI, P.; THAKUR, S.; LAL, S.; KHARE, S. Congenital CMV infection: diagnosis in symptomatic infants. Indian Journal of Medical Microbiology, v. 27, n. 3, p. 222-225, Jul./Sep. 2009.

GEREMIAS, A. L.; ALMEIDA, M; F.; FLORES, L. P. O. Avaliação das declarações de nascido vivo como fonte de informação sobre defeitos congênitos. Revista Brasileira de Epidemiologia, v. 12, n. 1, p. 60-68, 2009.

GIRISHA, K. M.; SHARDA, S. V.; PHADKE, S. R. Issues in counseling for Down syndrome. Indian Pediatric, v. 44, n. 2, p. 131-133, Feb. 2007.

GOLDFARB, C. A.; SATHIENKIJKANCHAI, A.; ROBIN, N. H. Amniotic constriction band: a multidisciplinary assessment of etiology and clinical presentation. The journal of bone and joint surgery, v. 91, n. 4, p. 68-75, Jul. 2009. 
GRAZIOSI, M. A. O. C.; SALGADO, M. A. C.; JÚLIO, C. M. C. Investigação epidemiológica em indivíduos portadores de fendas labiais e/ou palatinas. Revista da Faculdade de Odontologia, São José dos Campos, v. 3, n. 1, jan./jun. 2000.

GREEN, R. F.; DEVINE, O.; CRIDER, K. S.; OLNEY, R. S.; ARCHER, N.; OLSHAN, A. F.; SHAPIRA, S. K. Association of Paternal Age and Risk for Major Congenital Anomalies From the National Birth Defects Prevention Study, 1997 to 2004. Annals of Epidemiology. Jan. 2010.

GROUCHY, J. De; TURLEAU, C. Atlas des maladies chromosomiques. Paris: Expansion Scientifique Francaise, 1977.

GUERRA, F. A. R.; LLERENA JR., J. C.; GAMA, S. G. N.; CUNHA, C. B.; FILHA, M. M. THEME. Defeitos congênitos no município do Rio de Janeiro: uma avaliação através do SINASC (2000-2004). Cadernos de Saúde Pública, Rio de Janeiro, v. 24, n. 1, jan. 2008.

GUILAN, M. C.; CORREAA, M. C. D. V. Risk, medicine and women: a case study or prenatal genetic conselling I Brazil. Developing World Bioethics, v. 7, n. 2, p.78-85, Aug. 2007.

HAERI, S.; KHOURY, J.; KOVILAM, O.; MIODOVNIK, M. The association of intrauterine growth abnormalities in women with type 1 diabetes mellitus complicated by vasculopathy, American Journal of Obstetrics and Gynecology, v. 199, n. 3, P. 278.e1-278.e5, 2008.

HANSEN, C. A.; BARNETT, A. G.; JALALUDIN, B. B.; MORGAN, G. G. Ambient air pollution and birth defects in brisbane, australia. PloS One, v. 4, n. 4, 2009.

HARPER, P. Pratical genetic counseling. 5 ed. Oxford: Reed Elsevier, 2000.

HOROVITZ, D. D. G.; LLERENA JR., J. C.; MATTOS, R. A. Atenção aos defeitos congênitos no Brasil: panorama atual. Cadernos de Saúde Pública, Rio de Janeiro, v. 21, n. 4, jul./aug. 2005.

HOROVITZ, D. D. G.; CARDOSO, M. H. C. A.; LLERENA JR, J. C., MATTOS, R. A. Atenção aos defeitos congênitos no Brasil: características do atendimento e propostas para formulação de políticas públicas em genética clínica. Cadernos de Saúde Pública, Rio de Janeiro, v. 22, n. 12, p. 2599-2600, dez. 2006. 
IBIETA, M. F.; AMADOR, J. T. R.; CANO, J. M. B.; GONZÁLEZ-TOMÉ, M. I.;

MARTÍN, S. G.; GÓMEZ, M. N.; JOSÉ, M. I.; BECEIRO, J.; IGLESIAS, E.; PRIETO, L.; SANTOS, M. J.; GUARDIA, N. M.; ROA, M. A.; REGIDOR, J. Birth defects in a cohort of uninfected children born to HIV-infected women. Anales de Pediatría, Barcelona, v. 70, n. 3, p. 253-264, mar. 2009.

INTERNATIONAL SYSTEM FOR HUMAN CYTOGENETIC NOMENCLATURE. ISCN 2009: an international system for human cytogenetic nomenclature. Farmington: Karger, 2009.

IONESCU-ITTU, R.; MARELLI, A. J.; MACKIE, A. S.; PILOTE, L. Prevalence of severe congenital heart disease after folic acid fortification of grain products: time trend analysis in Quebec, Canada. BMJ, n. 338, v. 1673b, May 2009.

JONES, K. L. J. Padrões reconhecíveis de malformações congênitas. 6. ed. Rio de Janeiro: Elsevier, 2007.

KILSZTAJN, S.; ROSSBACH, A.; CARMO, M. S. N.; SUGAHARA, G. T. L. Assistência pré-natal, baixo peso e prematuridade no Estado de São Paulo, 2000 Revista de Saúde Pública, São Paulo, v. 37, n.3, jun. 2003.

LAMMER, E. J.; IOVANNISCI, D. M.; TOM, L.; SCHULTZ, K.; SHAW, G. M. Gastroschisis: a gene-environment model involving the VEGF-NOS3 pathway. American journal of medical genetics. Part C, Seminars in medical genetics, v. 148, n. 3, p.213-218, Aug. 2008.

LEITE, J. C. L.; STEIN, N. R.; TROVISCAL, L. P; GIUGLIANI, R. Programa de monitoramento de DC: experiência do estudo colaborativo latino-americano de malformações congênitas no HCPA. Revista do HCPA \& Faculdade de Medicina da Universidade Federal do Rio Grande do Sul, v. 3, p. 290-293, 2001.

LIASCOVICH, R.; RITTLERB, M.; CASTILLAC, E. E. Consanguinity in South America: Demographic Aspects. Human Heredity, v. 51, n. 1, p. 27-34, 2001.

LIN, A. E.; RASMUSSEN, S. A.; SCHEUERLE, A.; STEVENSON, R. E. Clinical Geneticists in Birth Defects Surveillance and Epidemiology Research Programs: Past, Present and Future Roles. Birth Defects Research (Part A), v. 85, p: 69-75. 2009.

LUND, C. H.; BAUER, K.; BERRIOS, M. Gastroschisis: incidence, complications, and clinical management in the neonatal intensive care unit. The Journal of Perinatal \& Neonatal Nursing, v. 21, n. 1, p. 63-8, Jan-Mar. 2007. 
MAJNEMER, A.; LIMPEROPOULOS, C.; SHEVELL, M. I.; ROHLICEK, C.;

ROSENBLATT, B.; TCHERVENKOV, C. New look at outcomes of infants with congenital heart disease. Pediatric Neurology, v. 40, n. 3, p. 197, 204, 2009.

MALTA, D. C.; DUARTE, E. C.; ALMEIDA, M. F.; DIAS, M. A. S. Lista de causas de mortes evitáveis por intervenções do sistema único de saúde do Brasil. Epidemiologia e Serviços de Saúde, Brasília, v. 16, n. 4, p. 233-244, out./dez. 2007.

MANDALA, J.; TORPEY, K.; KASONDE, P.; KABASO, M.; DIRKS, R.; SUZUKI, C.; THOMPSON, C.; SANGIWA, G.; MUKADI, Y. D. Prevention of mother-to-child transmission of HIV in Zambia: implementing efficacious ARV regimens in primary health centers. BMC Public Health, England, v. 9, n. 314, Aug. 2009.

MARAM, E.; UCHIMURA, T.T. Neonatal mortality: risk fact in south of Brazil. Revista Eletrônica de Enfermagem, v. 10, n. 1, p. 29-35, 2008.

MATERNA-KIRYLUK, A.; WIŚNIEWSKA, K.; BADURA-STRONKA, M.; MEJNARTOWICZ, J.; WIECKOWSKA, B.; BALCAR-BOROŃ, A.; CZERWIONKASZAFLARSKA, M.; GAJEWSKA, E.; GODULA-STUGLIK, U.; KRAWCZYŃSKI, M.; LIMON, J.; RUSIN, J.; SAWULICKA-OLESZCZUK, H.; SZWALKIEWICZWAROWICKA, E.; WALCZAK, M.; LATOS-BIELEŃSKA, A. Parental age as a risk factor for isolated congenital malformations in a Polish population. Paediatric Perinatal Epidemiology, v. 23, n. 1, p. 29-40. Jan. 2009.

MATHEWS, T.J.; .MACDORMAN, M. F. Infant Mortality Statistics from the 2005 Period Linked Birth/Infant Death Data Set. National Vital Statitcs Reports, v. 57, n. 2, p. 1-32, Jul. 2008.

MAZER, P.; GISCHLER, S. J.; KOOT, H. M.; TIBBOEL, D.; VAN DIJK, M.; DUIVENVOORDEN, H. J. Impact of a child with congenital anomalies on parents (ICCAP) questionnaire; a psychometric analysis. Health and Quality Life Outcomes, v. 6, n. 102, Nov. 2008.

MERCADO, O. E. S.; TORRES, A. M. L.; AGUILLE, R. D. B.; IBARRA, R. V.; CÁRDENAS, R. M.; ROLÓN, L. M. C. Prevalencia de politelia en escolares. Revista Mexicana de Pediatría, v. 65, n. 4, p.165-166, Jul./Ago. 1998.

MESQUITA, M. A.; SEGRE, C. A. M. Frequência dos efeitos do álcool no feto e padrão de consumo de bebidas alcoólicas pelas gestantes de maternidade pública da cidade de São Paulo. Revista brasileira de crescimento e desenvolvimento humano, v. 19, n. 1, p. 63-77, abr. 2009. 
METZGER, B. E.; BUCHANAN, T. A.; COUSTAN, D. R.; LEIVA, A.; DUNGER, D. B.; HADDEN, D. R.; HOD, M.; KITZMILLER, J. L.; KJOS, S. L.; OATS, J. N.;PETTITT, D. J.; SACKS, D. A.; ZOUPAS, C. Summary and Recommendations of the Fifth International Workshop-Conference on Gestational Diabetes Mellitus. Diabetes Care, v. 30, n. 2, p. 251260, Jul. 2007.

MIYAGUE, N. I.; CARDOSO, S. M.; MEYER, F.; ULTRAMARI, F. T.; ARAÚJO, F. H.; ROZKOWISK, I.; TOSCHI, A. P. Estudo Epidemiológico de Cardiopatias Congênitas na Infância e adolescência. Análise em 4.538 Casos. Arquivos Brasileiros de Cardiologia, São Paulo, v. 80, n. 3, p. 269-273, 2003.

MONTEIRO, C. A.; COSTA, L. F. C. Epidemiologia de malformações congênitas em recémnascidos nativivos do Hospital Universitário-Unidade Materno Infantil de São LuisMaranhão, Brasil. Revista do Hospital Universtiário/UFMA, v. 1, n. 1/2, p. 34-38, jan./ago. 2003.

MOORHEAD, P. S.; NOWEL, P. C.; MELLMAN, W. J.; BATTIPS, D. M.; HUNGERFORD, D. A. Chromosome preparations of leukocytes cultured from human peripheral blood. Experimental Cell Research, New York, v. 20, p. 613-616, Sep. 1960.

MOREIRA, L. M. A.; DIAS, A. L.; RIBEIRO, H. B. S.; FALCÃO, C. L.; FELÍCIO, T. D.; STRINGUETTI, C.; SANTOS, M. D. F. Associação entre o uso de abortificantes e defeitos congênitos. Revista Brasileira de Ginecologia e Obstretrícia, Rio de Janeiro, v. 23, n. 18, p. 517-521, sep. 2001.

MORRIS, J. K.; SAVVA, G. M. The risk of fetal loss following a prenatal diagnosis of trisomy 13 or trisomy 18. American Journal of Medical Genetics, New York, v. 146, n. 7, p. 827-32, Apr. 2008.

MURPHY, R. G.; WILLIANS, R. H.; HUGHES, J. M.; HIDE, G.; FORD, N. J.; OLDBURY, D. J. The urban house mouse (Mus domesticus) as a reservoir of infection for the human parasite Toxoplasma gondii: an unrecognised public health issue? International journal of environmental health research, v. 18, n. 3, p. 177-185, Jun. 2008.

NUSSBAUM, R. L.; McINNES, R.R.; WILLARD, H. F. Thompson \& Thompson:

Genética Médica. 7. ed. Rio de Janeiro: Guanabara Koogan, 2007.

OMIM, 2009. Disponível em: < http://www.ncbi.nlm.nih.gov/omim/>. Acesso em: 28 out. 2009. 
ORIOLI, I. M.; RIBEIRO, M. G.; CASTILLA, E. E. Clinical and epidemiological studies of amniotic deformity, adhesion, and mutilation (ADAM) sequence in a South American (ECLAMC) population. American Journal of Medical Genetic., v. 118A, p. 135-145, 2003.

ORMOND, G.; NIEUWENHUIJSEN, M. J.; NELSON, P.; TOLEDANO, M. B.; ISZATT, N.; GENELETTI, S.; ELLIOTT, P. Endocrine disruptors in the workplace, hair spray, folate supplementation, and risk of hypospadias: case-control study. Environmental Health Perspect, v. 117, n. 2, p. 303-307, Feb. 2009.

OTTAVIANI, G. Role of post-mortem investigations in determining the cause of sudden unexpected death in infancy. Archives of Disease in Childhood, v. 94, p. 170-171, 2009.

PACHECO, S. S.; SOUZA, A. I.; GUERRA, G. V. Q. L.; FILHO, M. B.; BAPTISTA, E. V. P.; MELO, M. I. B. Prevalência dos defeitos de fechamento do tubo neural em recémnascidos do Centro de Atenção à Mulher do Instituto Materno Infantil Prof. Fernando Figueira, IMIP: 2000-2004. Revista Brasileira de Saúde Materno Infantil, Recife, v. 6, n. 1, p. s35-s42, maio, 2006.

PACHECO, S. S.; BRAGA, C.; SOUZA, A. I.; FIGUEIROA, J. N. Efeitos da fortificação com ácido fólico sobre a prevalência de defeitos do tubo neural. Revista de Saúde Publica, v. 43 , n. 4 , p.565-571, aug. 2009.

PAVLINKOVA, G.; SALBAUM J. M.; KAPPEN, C. Maternal diabetes alters transcriptional programs in the developing embryo. BMC Genomics, v. 10, p. 274. Jun. 2009.

PENCHASZADEH, V. B. Genetic services in Latin America. Community Genetics, v. 7, $\mathrm{n}$. 4, p. 65-69, 2004.

PEREIRA, R. J. S.; ABREU, L. C.; VALENTI, V. E.; ALBUQUERQUE, W. D. M.; PEREIRA, S. C.; ARAÚJO, R.; NETO, M. L. F.; SANTOS, S. M. Frequência de malformações congênitas das extremidades em recém-nascidos. Revista Brasileira de Crescimento e Desenvolvimento Humano, São Paulo, v. 18, n. 2, ago. 2008.

PINTO, C. O.; NASCIMENTO, L. F. C. Estudo de prevalência de defeitos congênitos no Vale do Paraíba Paulista. Revista Paulista de Pediatria, São Paulo, v. 25, n. 3, set. 2007.

PINTO, J. A.; BLUMETTIII, F. C.; IHAIII, L. A. N.; TERASAKAIV, M. K.; SODRÉV, H.; ISHIDAVI, A. Avaliação da anatomia arterial no pé torto congênito através da ultrassonografia com doppler colorido. Acta Ortopédica Brasileira, São Paulo, v.16, n.5, 2008. 
RAMOS, J. L. A. M.; CARVALHO, M. H. B.; ZUGAIB, M. Caracterização

sociodemográfica e resultados perinatais das gestações com diagnóstico ultrassonográfico de malformação fetal. Revista da Associação Médica Brasileira, São Paulo, v. 55, n. 4, p. 447$451,2009$.

RASMUSSEN, S.A.; FRÍAS, J. L. Non-genetic risk factors for gastroschisis. American journal of medical genetics, v. 148C, n. 3, p. 199- 212, Aug. 2008.

RAY, J. G.; WYATT, P. R.; VERMEULEN, M. J.; MEIER, C.; COLE, D. E. Greater maternal weight and ongoing risk of neural tube defects after folic acid flour fortification. Obstetrics and Gynecology, v. 105, n. 2, p. 261-265, 2005.

SANTOS, L. M. P.; PEREIRA, M. Z. Efeito da fortificação com ácido fólico na redução dos defeitos do tubo neural. Cadernos de Saúde Pública, Rio de Janeiro, v. 23, n. 1, p. 17-24, jan. 2007.

SANTOS, G. H. N.; MARTINS, M. G.; SOUSA, M. S.; BATALHA, S. J. C. Impacto da idade materna sobre os resultados perinatais e via de parto. Revista Brasileira de Ginecologia e Obstetrícia, v.31, n.7, p. 326-334, 2009.

SAVITZ, D. A. How far can prenatal screening go in preventing birth defects? The Journal of Pediatrics, New York, v. 152, n. 1, p. 3-4, Jan. 2008.

SILVA, C. M. C.; GOMES, L. F. G. Reconhecimento clínico das cardiopatias congênitas. Revista da Sociedade de Cardiologia do Estado de São Paulo, v. 12, n. 15, set./out. 2002.

SHAW, G. M.; CARMICHAEL, S. L.; KAIDAROVA, Z.; HARRIS, J. A. Differential risks to males and females for congenital malformations among 2.5 million California births, 19891997. Birth Defects Research Part A: clinical and molecular teratology, v. 68, p. 953-958, 2003.

SMITH, J.; WHITEHALL, J. Sodium valproate and the fetus: a case study and review of the literature. Neonatal Network, v. 28, n. 6, p. 363-367, Nov-Dec. 2009.

SOUZA-FREITAS, J. A.; DALBEN, G. S.; FREITAS, P. Z.; SANTAMARIA JR., M. Tendência familial das fissuras lábio-palatais. Revista Dental Press de Ortodontia e Ortopedia Facial, Maringá, v. 9, n. 4, p. 74-78, jul./ago. 2004.

STEVENSON, D. A.; CAREY, J. C. Contribution of malformations and genetic disorders to mortality in a children's hospital. American Journal of Medical Genetics, v. 126, p. 393$397,2004$. 
SWEENEY, M. R.; STAINES, A.; DALY, L.; TRAYNOR, A.; DALY, S.; BAILEY, S. W.; ALVERSON, P. B.; AYLING, J. E.; SCOTT, J. M. Persistent circulating unmetabolised folic acid in a setting of liberal voluntary folic acid fortification. Implications for further mandatory fortification? BMC Public Health, v. 9, n. 295, Aug. 2008.

TAN, K. H.; TAN, T. Y. T.; TAN, J.; TAN, I.; CHEW, S. K.; YEO, G. S. H. Birth defects in Singapore: 1994 - 2000. Singapore Medical Journal, v. 46, n. 10, p. 545-552, 2005.

THONG, M. K.; HO, J. J.; KHATIJAH, N. N. A population-based study of birth defects in Malaysia. Annals of Human Biology, London, v. 32, n. 2, p. 180-187, Mar. 2005.

TORIELLO. H. V. Role of the dysmorphologic Evaluation in the Child with Developmental Delay. Pediatric Clinics of North America, v. 55, n. 5, p. 1085-1098, Oct. 2008.

TOWER, C. L.; ONG, S. S.; EWER, A. K.; KHAN, K.; KILBY, M. D. Prognosis in isolated gastroschisis with bowel dilatation: a systematic review. Archives of disease in childhood. Fetal and neonatal edition, Nov. 2008.

TUNÇBILEK, E.; ÖZGUÇ, M. Application of medical geneics in Turkey. Turkey Journau of Pediatric, v. 49, n. 4, p. 353-359. Oct./Dec. 2007.

UÇAR, S.; ZORLU, P.; SAHIN, G.; YILDIRIM, M.; USAK, E. Jeune syndrome (asphyxiating thoracic dystrophy): a case report. Tuberk Toraks, v. 57, n. 4, p. 413-416, 2009.

VAN BALEN, F.; VERDURMEN, J. E.; KETTING, E. Age, the desire to have a child and cumulative pregnancy rate. Human Reproduction, v. 12, n. 3, p. 623-627, Mar. 1997.

VASQUEZ-MANZANILLA, O.; DICKSON-GONZALEZ, S. M.; SALAS, J. G.; TEGUEDOR, L. E.; RODRIGUEZ-MORALES, A. J. Influence of mother VDRL titers on the outcome of newborns with congenital syphilis. Tropical Biomedicine, v. 25, n. 1, p. 58-63, Apr. 2008.

WANG, X.; GOMUTPUTRA, P.; WOLGEMUTH, D. J.; BAXI, L. Effects of acute alcohol intoxication in the second trimester of pregnancy on development of the murine fetal lung. American journal of obstetrics and gynecology, Saint Louis, v.197 n. 3, p. 269, Sep. 2007.

WEN, S. W.; LIU, S.; JOSEPH, K. S.; ROULEAU, J.; ALLEN, A. Patterns of infant mortality caused by major congenital anomalies. Teratology, v. 61, n. 5, p. 342-346, 2000. 
WORLD HEALTH ORGANIZATION. Community genetic services in Latin America and regional networks on medical genetics. report of a WHO consultation. Geneva: WHO, 2004.

WORLD HEALTH ORGANIZATION. Addressing the global challenges of craniofacial anomalies. Geneva: WHO, 2006 a.

WORLD HEALTH ORGANIZATION. Management of Birth defects anda Haemoglobin Disorders. Geneva: WHO, 2006b.

YANG, Q.; WEN, S. W.; LEADER, A.; CHEN, A. X. K.; LIPSON, J.; WALKER, M.

Paternal age and birth defects: how strong is the association? Human Reproduction, Oxford, v. 22, n. 12, p. 3265-3267, Dec. 2006. 


\title{
ANEXO A - Termo de Consentimento Livre e Esclarecido
}

(Conselho Nacional de Saúde, Resolução 196/96)

\begin{abstract}
Para uma investigação científica honesta e segura, a pessoa que vai participar do estudo, ou o seu responsável legal deve dar seu consentimento livremente, após ter sido muito bem informado sobre os riscos e benefícios do estudo.

É da responsabilidade do pesquisador lhe dar toda e qualquer informação necessária e solicitada. Este termo de consentimento, que foi aprovado pelo um Comitê de Ética da FAMERP (telefone: 3201-5700 ramal 5813), tem a finalidade de proteger o participante do estudo.
\end{abstract}

Este documento tem o objetivo convidar.

nascido em pelo qual o (a) senhor (a) é responsável legal, a participar do Projeto de Pesquisa "Estudo Genético Prospectivo de Recém-Nascidos e Natimortos com Defeitos Congênitos", que está sob a responsabilidade das pesquisadoras Prof ${ }^{\mathrm{a}}$. Dr ${ }^{\mathrm{a}}$. Agnes Cristina Fett Conte (Departamento de Biologia Molecular - FAMERP) e Camila Ive Ferreira Oliveira (IBILCE/UNESP), cujos telefones para contato são: (0xx17) 3201-5000 ramal 5813 (Comitê de Ética em Pesquisa) e 32015000, ramal 1931 (Laboratório de Genética).

O objetivo é avaliar o tipo de defeito de nascimento ocorrido, sua possível causa e consequências. Para atingir este objetivo, será necessária a coleta de um pouco de sangue do cordão umbilical ou da veia do braço do (a) seu(sua) recém-nascido(a). Será coletado por profissional especializado, no momento do parto (cordão umbilical), ou após o mesmo (braço). A retirada de sangue do cordão umbilical não dói e não oferece riscos ao bebê e é feita pelo ginecologista. No caso de coleta de sangue do braço os riscos para a saúde são dor, ardência ou mancha roxa no local da retirada do sangue. Contudo, para evitar que isso aconteça, a retirada será realizada por enfermeiro especializado, com todas as medidas de segurança e higiene necessárias.

Também será realizado um exame físico no recém-nascido, que incluirá a identificação de características de nascença e medidas do corpo, serão tiradas fotos em vistas frontal e lateral e realizada uma entrevista com a mãe ou os pais, no momento que acharem mais oportuno.

O sangue coletado será utilizado única e exclusivamente para atingir o objetivo 
deste estudo e após a sua utilização será descartado. É importante que você saiba que estes procedimentos já são feitos de rotina neste Hospital em todos os casos de nascimento de crianças com alguma alteração física e que este termo é uma solicitação para que os dados sejam divulgados e utilizados com propósitos unicamente científicos.

Para esclarecimento de dúvidas as pesquisadoras responsáveis podem ser contatadas pelo telefone ou pessoalmente. Em caso de ser detectada alguma alteração nos exames, os resultados serão muito bem esclarecidos $\mathrm{e}$ todas as informações/esclarecimentos serão oferecidos em sessão de Aconselhamento Genético, que será realizada pela pesquisadora orientadora deste estudo, em dia agendado, no Ambulatório de Genética. Também, todas as informações obtidas da sua participação serão consideradas confidenciais, ficando a identidade de toda sua família mantida em segredo, em qualquer situação.

As informações obtidas desta pesquisa só poderão ser divulgadas em reuniões ou revistas científicas e sem revelar o nome da criança ou de seus pais.

Se decidir não participar ou interromper a sua participação, em qualquer época, você não terá nenhum tipo de prejuízo, não perderá nenhum benefício e não precisará dar justificativas da sua atitude. É importante saber que sua participação não trará qualquer prejuízo financeiro, mas que também não terá qualquer tipo de remuneração.

Li este termo, recebi informações claras sobre a presente investigação, tive oportunidade de fazer perguntas e todas foram respondidas. Estou de acordo em participar livre e espontaneamente deste estudo e sei que, sob hipótese alguma receberei qualquer tipo de gratificação pela minha participação.

Entendi que este estudo poderá contribuir para o conhecimento das causas e das manifestações envolvidas no problema apresentado por meu (minha) filho (a), e que, dependendo do resultado, poderá auxiliar no diagnóstico e orientação genética para a minha família.

\section{Dou, portanto o meu consentimento para participação do (a) meu (minha)} filho (a).

Nome do responsável legal:

Vínculo: Pai( ) Mãe ( ) Outro ( ).

Quero receber os resultados dos exames? Sim ( ) Não ( ) 
Data:...................

Assinatura:

DECLARAÇÃO DE RESPONSBILIDADE: Expliquei a natureza, objetivos, riscos e benefícios desta investigação. Coloquei-me à disposição para perguntas e respondi a todas. Obtive o consentimento de maneira livre e me coloquei à disposição para qualquer outro esclarecimento pelo telefone (0xx17) 3201-5000 ramal 1931.

Pesquisador: Camila Ive Ferreira Oliveira

RG:33.014.044-9

Data:...

Assinatura: 


\section{ANEXO B - Protocolo de Pesquisa de Recém-Nascidos e Natimortos com DC}

Número:

I. IDENTIFICAÇÃO

RG.:

Nome:

Data do nascimento: / / Sexo:

Tipo sanguíneo:

II. DADOS DOS PAIS

Nome da mãe:

Data do nascimento: / / Etinia:

Profissão:

Nome do pai:

Data do nascimento: / / Etinia:

Profissão:

Idade da mãe ao nascimento do propósito:

Endereço: Telefone:

\section{ANTECEDENTES GESTACIONAIS}

1.Gestação:

termo pré- termo

Obs.:

Pré - natal

$\operatorname{sim}$ não

não neste H.B.

outro local

Ultrassom:

$\operatorname{sim}$ não

Outros exames:

sim não

Obs.:

2. Doenças na gravidez:

Febre

sim não

Hemorragia

Doenças infecciosas

Diabetes

$\operatorname{sim}$ não

Epilepsia

$\operatorname{sim}$

não

sim não

Outras doenças crônicas:

3.Fatores químicos/físicos na gravidez:

Medicamentos:

sim não

Uso de contraceptivos orais:

$\operatorname{sim}$

Alcoolismo:

$\operatorname{sim}$

Tabagismo:

$\operatorname{sim}$

Usuário de drogas:

$\operatorname{sim}$

Exposição profissional:

sim

não

Fez tratamento para engravidar:

$\operatorname{sim}$

não

Outros:

4. Parto: normal cesárea fórceps

Obs.: 


\begin{tabular}{|c|c|c|c|c|c|}
\hline Reanimação & $\operatorname{sim}$ & não & não sabe & & \\
\hline Choro & imediato & demorado & não sabe & & \\
\hline Cianose & $\operatorname{sim}$ & não & não sabe & & \\
\hline Oxigenoterapia & $\operatorname{sim}$ & não & não sabe & & \\
\hline Incubadora & $\operatorname{sim}$ & não & não sabe & & \\
\hline Icterícia neo-natal & $\operatorname{sim}$ & não & não sabe & & \\
\hline Fototerapia & $\operatorname{sim}$ & não & não sabe & & \\
\hline Hemorragias & $\operatorname{sim}$ & não & não sabe & Início: & Duração: \\
\hline Exame neurológico & $\operatorname{sim}$ & deprimido & exaltado & & \\
\hline Apgar: & & & & & \\
\hline
\end{tabular}

5. Gestações anteriores:

$\mathrm{N}^{\mathrm{o}}$ de gestações:

Tipo de parto: normal ( ) cesária ( ) fórceps ( )

Sexo

$\mathrm{F}(\quad) \quad \mathrm{I}(\quad)$

$\mathrm{N}^{\circ}$ de nativivos:

normal ( )

$\mathrm{N}^{\mathrm{o}}$ de abortos: $(\quad)$

$\mathrm{N}^{\mathrm{o}}$ de natimortos:

Todos filhos do mesmo pai:

sim não

Obs.:

IV. ANTECEDENTES FAMILIAIS

Neoplasias $\quad \operatorname{sim}$ não

não epilepsia $\quad$ sim não

Diabetes

sim não

DSTs

$\operatorname{sim}$ não

Recorrência familial do mesmo problema:

Alterações congênitas na irmandade:

doenças cardíacas

sim não

Alterações congênitas na família:

$\begin{array}{ll}\operatorname{sim} & \text { não } \\ \operatorname{sim} & \text { não } \\ \operatorname{sim} & \text { não }\end{array}$

Obs.:

3.Heredrograma:

sim não 